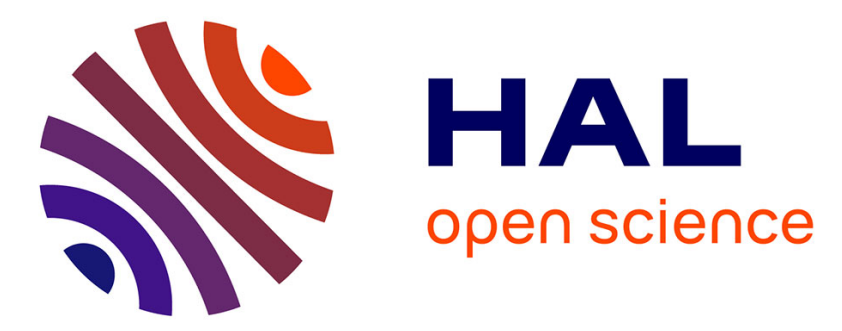

\title{
Theoretical Insights into the Interaction of Oxygenated Organic Molecules and Cobalt(II) Precursor with $\gamma$-Al 2 O 3 Surfaces
}

Brice Firmin Ngouana Wakou, Manuel Corral Valero, Pascal Raybaud

\section{To cite this version:}

Brice Firmin Ngouana Wakou, Manuel Corral Valero, Pascal Raybaud. Theoretical Insights into the Interaction of Oxygenated Organic Molecules and Cobalt(II) Precursor with $\gamma$-Al 2 O 3 Surfaces. Journal of Physical Chemistry C, 2018, 122 (34), pp.19560-19574. 10.1021/acs.jpcc.8b05071 . hal01940830

\author{
HAL Id: hal-01940830 \\ https: / hal-ifp.archives-ouvertes.fr/hal-01940830
}

Submitted on 30 Nov 2018

HAL is a multi-disciplinary open access archive for the deposit and dissemination of scientific research documents, whether they are published or not. The documents may come from teaching and research institutions in France or abroad, or from public or private research centers.
L'archive ouverte pluridisciplinaire HAL, est destinée au dépôt et à la diffusion de documents scientifiques de niveau recherche, publiés ou non, émanant des établissements d'enseignement et de recherche français ou étrangers, des laboratoires publics ou privés. 


\title{
Theoretical insights into the interaction of oxygenated organic molecules and cobalt(II) precursor with $\gamma-\mathrm{Al}_{2} \mathrm{O}_{3}$ surfaces.
}

\author{
Brice Firmin Ngouana Wakou, Manuel Corral Valero ${ }^{*}$, Pascal Raybaud \\ IFP Energies nouvelles, Direction Catalyse et Séparation, rond-point de l'échangeur de \\ Solaize, BP 3, 69360 Solaize, France \\ *Corresponding author: manuel.corral-valero@ifpen.fr
}

\begin{abstract}
We have investigated the interaction of two common oxygenates, ethylene glycol (EG) and acetic acid (AA) with the main exposed (100) and (110) surfaces of $\gamma-\mathrm{Al}_{2} \mathrm{O}_{3}$ surfaces by quantifying the thermochemistry of the drying process. Using Density Functional Theory (DFT) calculations we have calculated the thermodynamically favorable free energies, and identified the adsorption modes and sites involved for both molecules with the main exposed (100) and (110) surfaces of $\gamma-\mathrm{Al}_{2} \mathrm{O}_{3}$. We show that the affinity of EG for alumina surfaces sites is stronger than AA after drying. EG preferentially interacts through hydrogen bonds on the hydroxyl nests of the (100) surface, while it may interact through Al-O bonds on the (110) surface. AA is predominantly deprotonated and interacts as acetate anions through Al-O bonds on the (100) surface, and hydrogen bonds on the (110) surface. We then propose a quantitative comparison of the interaction of $\mathrm{Co}^{2+}$ hexaaquo precursor with the same $\gamma-\mathrm{Al}_{2} \mathrm{O}_{3}$ surfaces. The adsorption configurations of the two organic molecules which may hinder the epitaxial growth of cobalt oligomers on alumina surfaces are identified. The thermodynamical analysis shows that EG and AA are less stable than the Co precursors after drying. The strong stabilization of Co precursors is attributed to its epitaxial relationship with the dried alumina
\end{abstract}


surfaces as found in [Angew. Chem. Int. Ed. 2015, 54, 6824-6827] but also to entropic effects involved in the drying process (vapor release and counter-ion decomposition in the gas phase). We finally discuss how these effects can be circumvented by changing the conditions of the impregnation and drying steps.

\section{Introduction}

Metal oxides are key materials in heterogeneous catalysis. Amongst them, $\gamma-\mathrm{Al}_{2} \mathrm{O}_{3}$, also referred to as "alumina", is one of the most widespread support in industry ${ }^{1}$. Although the main role in a catalytic process is attributed to the so-called active phase (generally a metal), aluminas, acting as "carrier" at the backstage, also have their share of fame in the overall performance of the catalytic material. Once a suitable metallic phase/support couple is identified for a given catalytic reaction, much of the efforts to fine-tune the heterogeneous catalyst focus on the optimization of the concentration, structural (morphology, size) and electronic properties of the metallic active phase, and on the optimization of the textural properties of the support itself. However, the extent to which we may modify any of these characteristics depend on the intrinsic metal support interactions (MSI) between, on the one hand, the forefront active phase and, on the other hand, the alumina carrier at the backstage.

Although many researchers have investigated MSI effect for a long time ${ }^{2-5}$, the interplay between the active phase and the alumina carrier represents a challenging question from the preparation steps to the working state of the catalyst. However, it is still today 
assessed indirectly from experiment, rationalized with chemical intuition and optimized by trial and error. Even if we focus on the relevant case of alumina supported catalysts, the preparation steps of the catalyst are still scarcely investigated by theoretical approaches ${ }^{6-8}$.

During the preparation steps of the catalyst (impregnation and drying), it is well known that the metallic precursors interact with the hydroxyl groups and/or aluminum sites exposed on the aluminas' surface and this chemical interaction depends on several parameters $\left(\mathrm{pH}\right.$, counter-ions,...) imposed by the aqueous mother solution ${ }^{4}$. If we consider relevant catalytic systems for low temperature Fischer-Tropsch (FT) synthesis ${ }^{9,10}$ or for hydrotreating (HDT) ${ }^{11}$, cobalt, nickel and molybdenum are often a key component of the active phases. Sarrazin et al. have shown by infrared analysis that the interaction of oxomolybdenum anions with $\gamma$-alumina surfaces occurs through an exchange of the neutral and basic and hydroxyls 12. The relationship between the alumina surface structure and the reactivity of surface hydroxyls has been further explored for the adsorption of Mo oxoanions and $\mathrm{Ni}^{2+}$ on both the (0001) and (1102) $\alpha$-alumina monocrystal surfaces ${ }^{13,14}$. It was shown that the oxide support is playing different roles depending on the exposed crystal surface. On $\gamma$-alumina, DFT calculations have also identified the most favourable adsorption sites of $\mathrm{Co}^{\mathrm{II}}$ hydrated ions on the (100) and (110) hydrated surfaces of $\gamma-\mathrm{Al}_{2} \mathrm{O}_{3}$ corresponding to low water pressure after the drying step and thus in the absence of the liquid solvent ${ }^{6}$. In particular, Co anchors on both $\gamma$ $\mathrm{Al}_{2} \mathrm{O}_{3}$ (100) and (110) surfaces by substitution of surface $\mathrm{OH}$ groups, and by the formation of additional Co-O bonds with surface oxygen atoms leading to strong epitaxial interactions. An important step further in the preparation methods was made by adding oxygenated organic additives (such as polyols, carboxylic acids, ...) to modify and improve the deposition of cobalt metallic precursors of FT and HDT catalysts ${ }^{3}$. This subject attracts a vivid scientific interest as illustrated in in scientific publications devoted to the role of these oxygenated additives on alumina supported cobalt FT ${ }^{15}$ and CoMoS HDT catalysts ${ }^{16,17}$. However, the 
understanding of the modes of interaction of such organic additives remains unclear. It is argued that the use of additives might displace the metallic species at the alumina surface and thus reduce the loss of the metal in the support and improve the dispersion or the activation process. These oxygenated organic molecules can be impregnated at different steps of the preparation which impacts the physico-chemical properties of the final FT or HDT catalyst ${ }^{16,18-21}$ : on the alumina support before any metallic precursors (pre-impregnation), together with the metallic precursors (co-impregnation), after the metallic precursors and first drying (post-impregnation). In each case, the following pairs of complexation processes are in competition: Co-water, Co-additive, Co-surface, surface-water, and finally surface-additive. Well quantified interactions of all these processes are still missing to tune the choice of additives with the adapted protocol of preparation.

A second important case where the interaction of organic molecules with alumina support plays a key role concerns the preparation of the support itself, and the tuning of its textural properties during hydrothermal treatments ${ }^{22-24}$. For instance, alumina supports are often preimpregnated (that is, before the metal deposition), with AA in order to increase their porosity. Although this has beneficial effects in some catalytic applications, such as the hydrotreatment of petroleum residues ${ }^{23}$, it may be deleterious for the reducibility of the active phase ${ }^{9,25}$.

A last important application, where the interactions of metal and organic additives with the support may play a key role, is related to the stability of alumina support during specific reaction conditions, in particular when water is a byproduct of the targeted reaction, such as in FT synthesis or in biomass conversion ${ }^{26}$. Several works have shown that adding metallic elements ${ }^{27}$ or oxygenated additives ${ }^{10,28-31}$ may prevent the transformation of alumina into boehmite in hydrothermal conditions. It may thus be relevant to better quantify the chemical interaction of such metallic or oxygenated species with the alumina support. 
In this theoretical work, we focus our attention on the interactions of acetic acid (AA), ethylene glycol (EG) and compare them with those of cobalt(II) hexaaquo precursors with the adsorption sites of $\gamma-\mathrm{Al}_{2} \mathrm{O}_{3}$. One should bear in mind that the two organic molecules studied in this work are potential candidates to be used for regulating metal-support interactions during the preparation of alumina supported metal-catalysts.

In the following sections we will first present the theoretical methodology. We then present results on the adsorption of AA and EG for on the two relevant surfaces of alumina, that is, the (110) and (100) surfaces. For that purpose, we will use the relevant alumina surface models from the theoretical works of Digne et al. ${ }^{32,33}$ that have been already applied to study MSI ${ }^{34-39}$ and alumina-water interface ${ }^{40}$. Then we will compare these results with the case of cobalt(II) species adsorbed on the same surface to identify how AA and EG molecules can actually impact this cobalt-surface interaction. In particular, we will make use of the results from a recent paper in which the interaction of Co with this support was studied ${ }^{6}$. Lastly we draw the conclusions and present our perspectives for future work.

\section{Methodology}

The (100) and (110) $\gamma$-alumina surface models used in this work are those developed by Digne et al. ${ }^{32,33}$. In the conditions of a slight drying between room temperature and $50^{\circ} \mathrm{C}$, both surfaces are considered in their highest hydroxylation state. The structural changes occurring during the hydroxylation of the dry (100) and (110) surfaces of $\gamma$-alumina are well explained elsewhere ${ }^{33,41}$. There are a lot of hydroxyl groups on these surfaces (Figure 1a) that offer many different possibilities for the adsorption of the organic molecules such as acetic acid (AA) or ethylene glycol (EG). Note that we will consider not only the adsorption on the hydroxyls but also the exchange of these hydroxyls with the incoming molecules. 


\subsection{Simulated systems}

\subsubsection{Adsorption at high surface coverage}

Since we have to carry out an extensive exploration of the potential energy surface to find out the most favorable adsorption configurations for these two molecules on both surfaces, it makes sense to start our calculations in the smallest (1x1) simulation cells (Figure 1a) that are obviously less demanding in term of computational resources than the larger cells: $(2 \times 3)$ and $(2 \times 2)$ for (100) and (110) surface respectively. Larger cells are investigated further in our work to explore surface coverage effects (Figures S1.2 and S1.3). Hence we start by studying the adsorption of 1 AA/EG molecule in this smaller cell, which corresponds to surface coverage values $\theta_{(100)}=2.15$ molecules $/ \mathrm{nm}^{2}$, and $\theta_{(110)}=1.49$ molecule $/ \mathrm{nm}^{2}$, respectively for the (100) and (110) surfaces. 
(a)

(b)

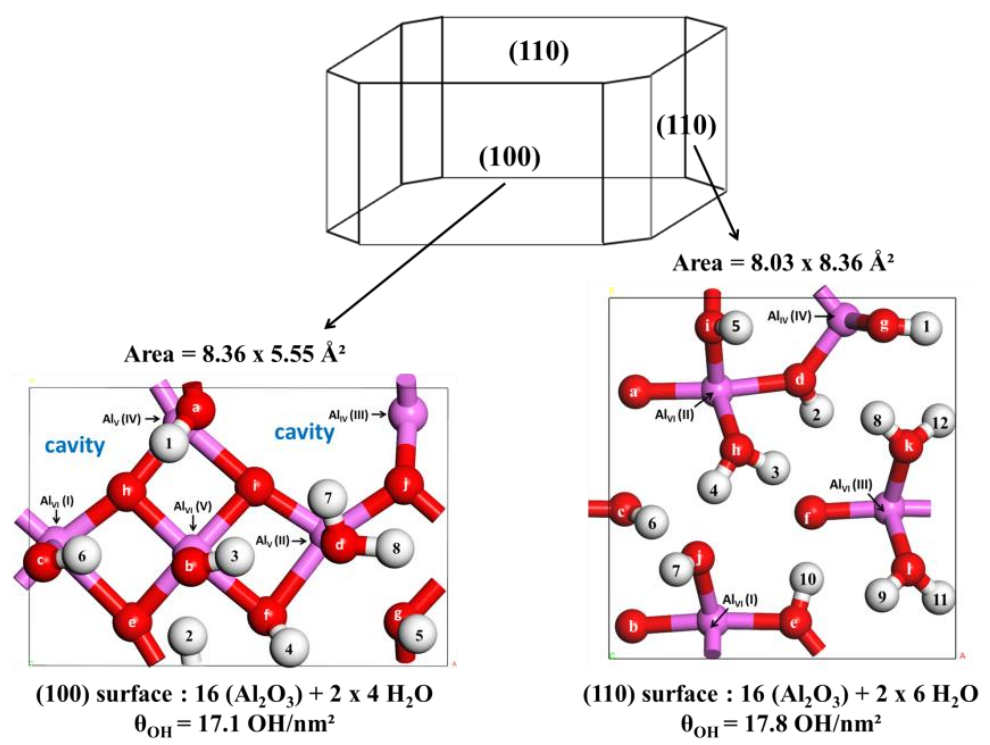

(100) surface

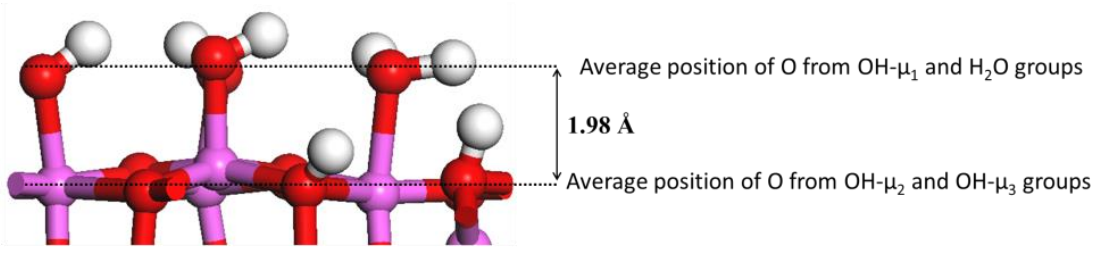

(110) surface

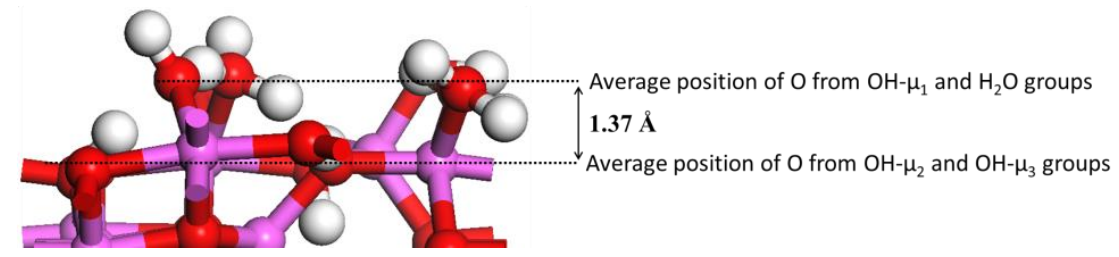

Figure 1. (a) Top view of the (100) and (110) hydroxylated slabs of $\gamma$-alumina with surface cavities (see Figure S1.2 for the larger systems) indicated for the (100). The aluminum Lewis acid sites (LAS) are numbered by the roman numerals in brackets and their coordination numbers are provided as indices. The surface oxygen and hydrogen atoms of the Brønsted acid sites (BAS) are denoted by letters and arabic numerals respectively. The total number of $\mathrm{Al}_{2} \mathrm{O}_{3}$ units is also indicated for each surface, as well as the surface area and the hydroxyl coverage. Color code: pink (aluminum), red (oxygen), and white (hydrogen). (b) The rugosities of the (100) and (110) surfaces of $\gamma$-alumina are compared as a function of the relative positions of the different types of $\mathrm{OH}$ surface groups.

To find out the most favorable adsorption configurations for these molecules on the (100) and (110) surfaces of $\gamma$-alumina, adsorption free energies $(\Delta \mathrm{G})$ were calculated according to the reaction scheme in Figure 2. This has been undertaken for several optimized adsorption configurations (see the surface-molecule system in Figure 2). The two 
hydroxylated (100) and (110) slabs with respective thicknesses of $\sim 20 \AA$ and $\sim 15 \AA$ (referred to as "surface" in Figure 2) and the molecule in solution (referred as "molecule $(1)$ ") were taken as the reference systems before adsorption. In order to mimic the dry state (gas phase) a vacuum of $25 \AA$ thickness was created on top of the surfaces before and after adsorption (Figures S1.2a and S1.3a). It should be mentioned that the simulation boxes with isolated molecules (in the liquid and gas phases) were created separately for the (100) and (110) slabs in order to keep consistency in the box dimensions of all the sub-systems involved in the adsorption process to avoid errors that may appear due to lateral interactions.

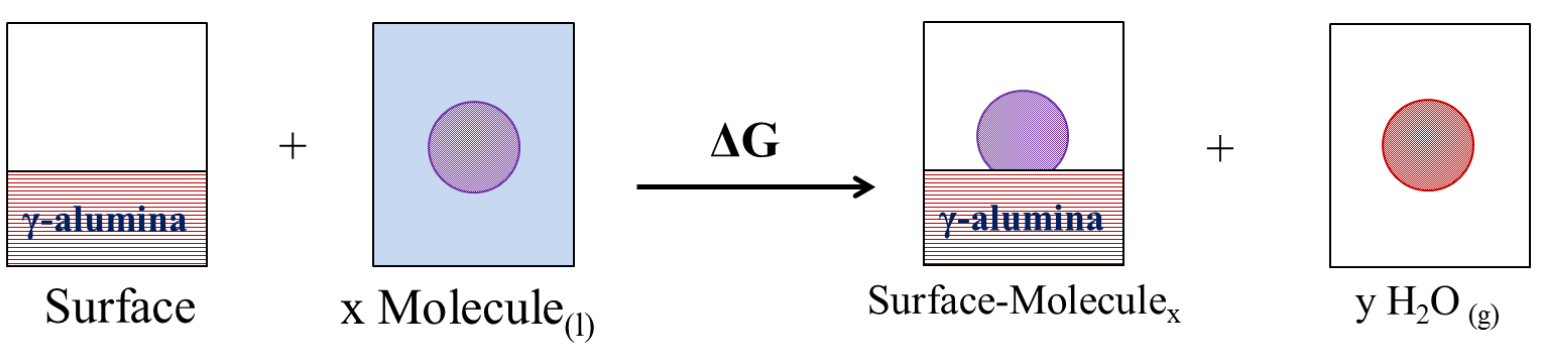

Figure 2. Schematic representation of the impregnation reaction of dried $\gamma$-alumina by a solution of acetic acid or ethylene glycol followed by drying at $\mathrm{T}=298 \mathrm{~K}$, with $\mathrm{x}$ the number of adsorbed AA or EG molecules $(1 \leq \mathrm{x} \leq 6)$ and $\mathrm{y}$ the number of desorbed water molecules during the reaction $(0 \leq \mathrm{y} \leq 6)$.

Around thousand adsorption configurations were generated for both molecules on the (100) and (110) surfaces to be used as starting points for geometry optimization calculations based on the various schemes provided in Figure 3. In these configurations the molecule can be either dissociated or non-dissociated, and its interaction with the surface can occur through coordinate bonding with Lewis adsorption sites (LAS) indicated by the aluminum atoms in Figure 1a, or through hydrogen bonding with Brønsted adsorption sites (BAS) involving both oxygen and hydrogen atoms of hydroxyls in Figure 1a. One should note that adsorption on LAS $\mathrm{Al}_{V}$ or $\mathrm{Al}_{\mathrm{VI}}$ implies simultaneously the removal of one surface $\mathrm{OH} / \mathrm{H}_{2} \mathrm{O}$ group, whereas 
it is not the case for $\mathrm{Al}_{\mathrm{IV}}$ (to be discussed later). When the organic molecule is linked to the surface through one of its two oxygen atoms it is referred as to monodentate adsorption. If the two oxygen atoms are implied in molecule-surface connections it is considered as bidentate adsorption. Also if only one surface site (Lewis or Brønsted) interacts with the molecule, then we denominate this configuration either a LAS or a BAS adsorption. Otherwise if there are two or more interacting surface sites, we call them LAS-LAS, BAS-BAS or mixed LAS-BAS adsorption modes. A schematic representation of thecorresponding adsorption configurations is provided in Figures $4 \mathrm{a}$ and $4 \mathrm{~b}$ respectively for AA and $\mathrm{EG}$.

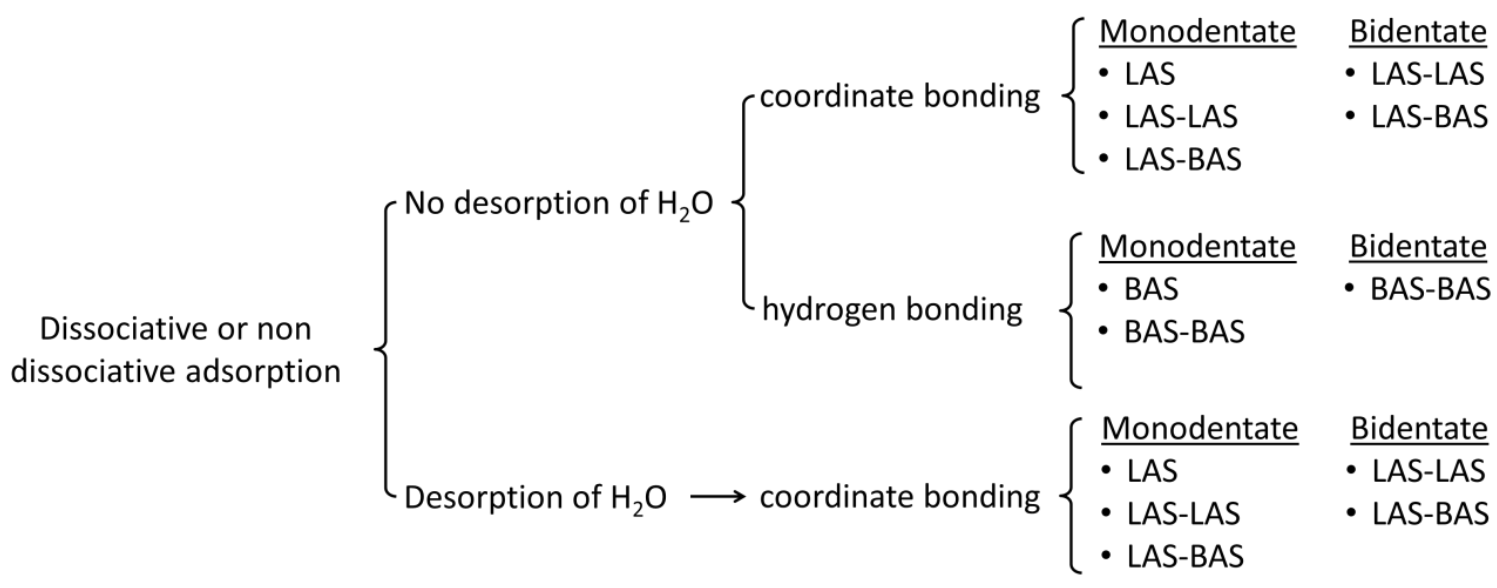

Figure 3. Tree representation of the different adsorption modes and reactions involved during the generation of the starting adsorbed structures (before geometry optimization) of AA and EG on the (100) and (110) of $\gamma$-alumina. The adsorption may be dissociative or nondissociative, and in both situations we have to consider whether a water molecule desorbs from the surface or not, and if the molecule-surface interactions occurs through hydrogen bonds or iono-covalent $\mathrm{Al}-\mathrm{O}$ bonds. 
(a)

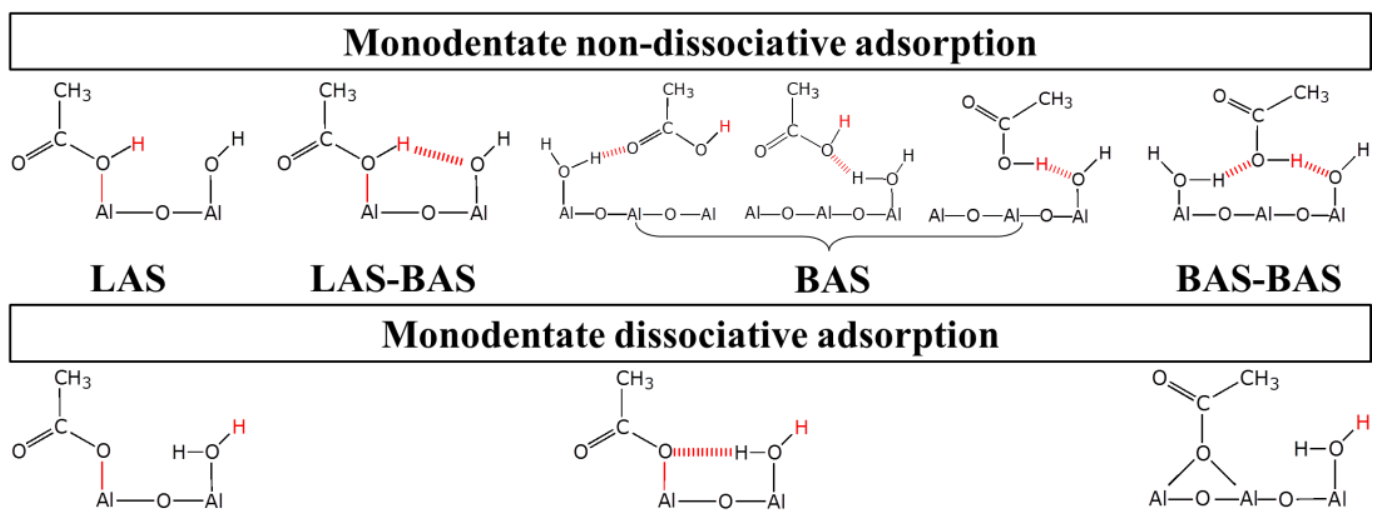

LAS

LAS-BAS

LAS-LAS

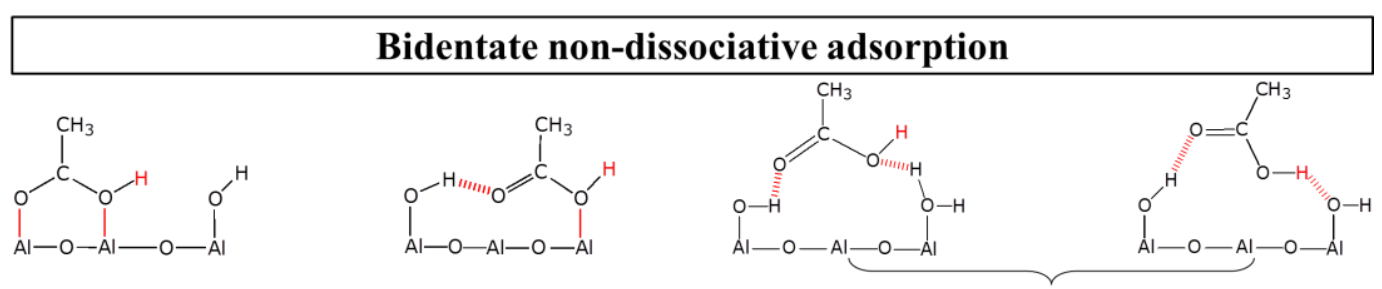

LAS-LAS

LAS-BAS

BAS-BAS

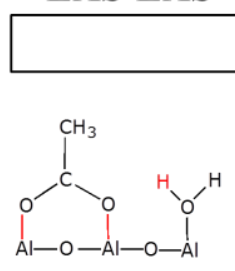

LAS-LAS

\section{Bidentate dissociative adsorption}

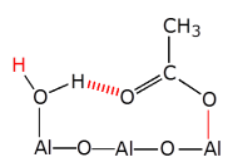

LAS-BAS

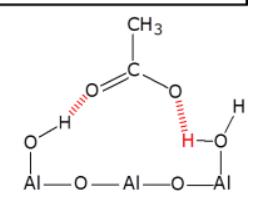

BAS-BAS 
(b)

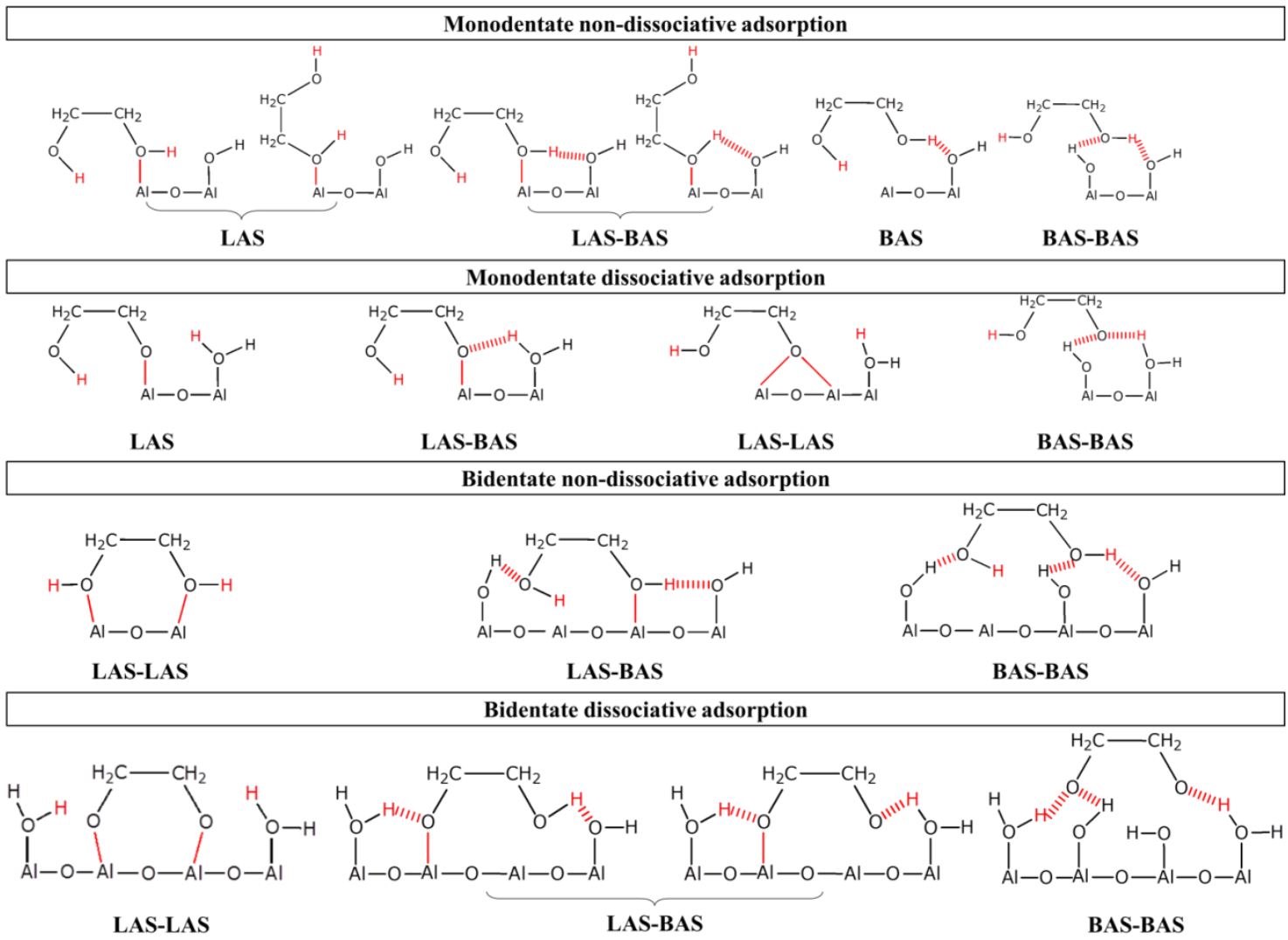

Figure 4. Schematic representation and denomination of the different initial adsorption modes of AA (a) and EG (b) sorted as a function of the reaction type (dissociative/non dissociative) and adsorption modes (LAS/BAS/LAS-LAS/BAS-BAS/LAS-BAS). Line code: Dashed red represent hydrogen bonds, plain red represent Al-O iono-covalent bonding.

For a given initial adsorbed configuration, several other structures were generated by rotating the molecules around the Al-O bond (LAS) or C-C bond (BAS) as illustrated in Figure S1.1 in the case of AA. When the AA and EG molecules are dissociated upon adsorption, the proton is transferred alternately on each of the surface oxygen atoms and $\mathrm{OH}$ groups (Figure 1a) and this creates additional configurations. Note that the proton removed from the organic molecule upon dissociation can also combine with the $\mathrm{OH}$ group of the adsorption site to form a $\mathrm{H}_{2} \mathrm{O}$ molecule that desorbs when the organic molecule binds to 5fold or 6-fold $\mathrm{Al}$ atoms. It is well known that EG does not dissociate in water. However 
during the generation of our initial adsorbed configurations on the (100) surface, we tried the simultaneous dissociation of the two protons of the OH groups of EG. It appeared that the EG molecule recovers at least one of the dissociated protons after geometry optimization. This observation prevented us from repeating the same procedure on the (110) orientation. Moreover, in all the adsorbed systems generated for acetic acid following the previously mentioned details, two AA molecules were simultaneously adsorbed on the two sides of the slabs on the same adsorption site in order to avoid dipole formation. However, we noticed that the energetic difference between the slabs with induced dipole (that appear due to the adsorption of only one molecule on one side of the slab) and the one with no dipole is negligible $(0.002 \mathrm{eV})$. Hence for EG only one side of the slabs was considered, and the same reasoning was applied for adsorbed systems at lower surface coverages (i.e.: larger supercells) that are discussed hereafter.

\subsubsection{Effect of surface coverage}

The adsorption configurations after geometry optimization are classified in different categories based on the adsorption modes (LAS, BAS or mixed) and reaction types (dissociative or non-dissociative) mentioned above. From this classification the most energetically favorable configurations of the most representative categories were selected for both AA and EG molecules. Larger simulation cells were created from these selected configurations (see Figures S1.2 and S1.3) and re-optimized in order to refine their structures and free energies values. Obviously, the simulation boxes for reference systems in Figure 2 (that are involved in our free energy calculations) were also enlarged accordingly in order to cancel out lateral interactions. Enlarged systems contain 6 AA/EG molecules in the $(2 \times 3)$ (100) cell (Figures S1.2c for $\theta=2.15$ ) and 4 AA/EG in the $(2 \times 2)(110)$ cell ( Figures S1.3c for $\theta=1.49$ ). From these structures AA/EG molecules were removed as shown in Figures $\mathrm{S} 1.2 \mathrm{c}$ (for the (100) surface) and S1.3c (for the (110) surface) in order to generate systems at lower 
surface coverage values. The objective here is to study how the number of adsorbed molecules affects the adsorption free energies and structures of AA and EG on the two surfaces. For a straightforward comparison of the data obtained at different surface coverages, we keep the same definition of the adsorption energy used before as shown in Figure 2, with $\mathrm{N}=1,2,3,4,6$ on the (100) surface and $\mathrm{N}=1,2,3,4$ for the (110) surface. For all $\mathrm{N}$ values our reference state is the hydroxylated $\gamma$-alumina surface. Therefore for $\mathrm{N}>1$ we have a simultaneous adsorption of 2 or more AA/EG molecules on the surface. For simplicity, we consider that for a given adsorption configuration, all the AA/EG molecules are adsorbed at identical adsorption sites on the surface, and through the same adsorption mode and following the same reaction type.

\subsubsection{Case of the cobalt system}

The calculations carried out in this part were achieved by making use of the large simulations cells as those mentioned in section 2.1.2 for AA and EG. For this purpose, we have reproduced the final cobalt adsorbed configurations reported in Ref. ${ }^{6}$ on the (100) and (110) hydroxylated surface models (Figure S1.4) and these structures were further optimized with our set up. In particular, the slabs we used and the geometry optimization procedure differ somehow from Ref. ${ }^{6}$ who used a thinner slab. Hence we recalculate the energy values according to the scheme given in Figure S3.1.

For the free energy calculations, our reference cobalt complex is the charged $\left[\mathrm{Co}\left(\mathrm{H}_{2} \mathrm{O}\right)_{6}\right]^{2+}$ in an aqueous solution rather than the neutral gas phase $\mathrm{Co}(\mathrm{OH})_{2}\left(\mathrm{H}_{2} \mathrm{O}\right)_{2}$ complex used in Ref. ${ }^{6}$, which explains the different energy values The use of this reference solvated state was necessary to make a coherent comparison with the solvated AA and EG molecules. For that, three separate simulations boxes were created for the simulation of $\left[\mathrm{Co}\left(\mathrm{H}_{2} \mathrm{O}\right)_{6}\right]^{2+}, \mathrm{H}^{+}$and $\mathrm{NO}_{3}{ }^{-}$counter-ions. For these systems we used a simulation cubic box 
of size $40 \AA$, as we have noticed that the electronic energies converge (less than $0.04 \mathrm{eV}$ difference) for a box size $\geq 30 \AA$ and the implicit solvent model used (see below).

According to thermodynamic data, after drying at $300 \mathrm{~K}, \mathrm{H}_{2} \mathrm{O}, \mathrm{N}_{2}$ and $\mathrm{O}_{2}$ should be the major products released in the gas phase. However, it is well known that the decomposition of nitrate ions is kinetically hindered. Hence, we decomposed the overall energy change of Co nitrate adsorption into two steps (see Section S3 and Figure 5 below): a) the surface adsorption of $\mathrm{Co}(\mathrm{II})$ ions on the surface and b) the decomposition of $\mathrm{NO}_{3}{ }^{-}$ions into $\mathrm{N}_{2}, \mathrm{O}_{2}$ and water.

(a)

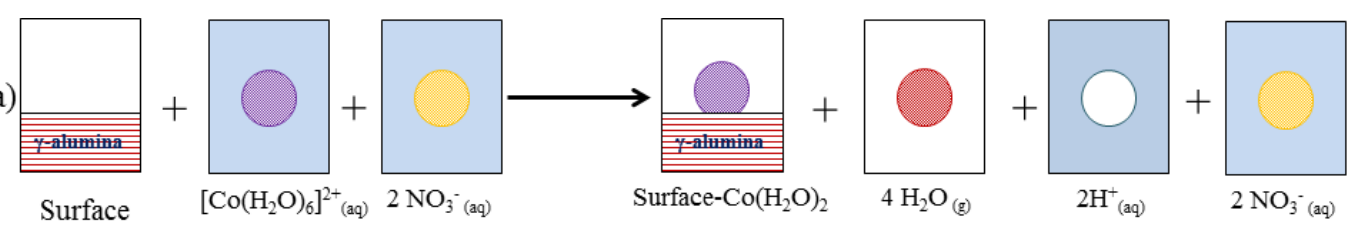

(b)

$$
2 H_{(a q)}^{+}+2 \mathrm{NO}_{3}^{+}(a q) \rightarrow \mathrm{N}_{2(g)}+\frac{5}{2} \mathrm{O}_{2(g)}+\mathrm{H}_{2} \mathrm{O}_{(g)}
$$

(a) + (b)

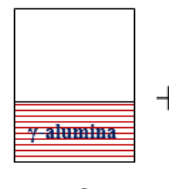

Surface

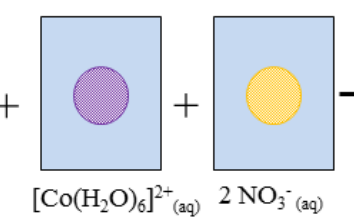

Surface- $\mathrm{Co}\left(\mathrm{H}_{2} \mathrm{O}\right)_{2}$

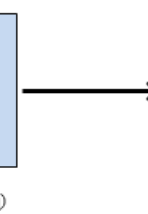

Figure 5: Schematic representation of the impregnation reaction of $\gamma$-alumina by a solution of hexaaquacobalt(II) nitrate followed by drying at $\mathrm{T}=298 \mathrm{~K}$. The overall reaction is decomposed into: equation (a) the adsorption of the hexaaquacobalt (II) complex and the release of two surface $\mathrm{H}^{+}$ions (here nitrate ions appears as spectators in both sides of the equation) and equation (b) the decomposition of $\mathrm{NO}_{3}{ }^{-}$ions to yield water, nitrogen and oxygen. In (a) "surface" denotes the reference (100) or (110) slabs and "surface-Co( $\left.\mathrm{H}_{2} \mathrm{O}\right)_{2}$ " is the system with the $\mathrm{Co}\left(\mathrm{H}_{2} \mathrm{O}\right)_{2}$ complex placed on the reference surfaces so as to reproduce the local adsorption environmentreported in Ref. ${ }^{6}$. 
Equation a) allows a comparison for the adsorbate-surface interactions between the organic molecules and the Co precursor, whereas the sum of both equations a and b provides the overall energy change due to the metal impregnation and counter-ion decomposition processes. Moreover, since equation b) is expected to be kinetically hindered, the energy change of equation a and equation $a+b$ could be interpreted, respectively, as the upper and lower limits of the energy change during the impregnation of cobalt nitrate on alumina.

To explore more rapidly the coverage trends, we only performed calculations for the adsorption of a single complex, that corresponds to surface coverage values of $\theta_{(100)}=0.36$ $\mathrm{Co} / \mathrm{nm}^{2}$ or $\theta_{(110)}=0.38 \mathrm{Co} / \mathrm{nm}^{2}$. We determined the difference between our adsorption energies and the ones reported in Ref. ${ }^{6}$ et al. at these $\theta$ values, and then we considered the differential energy to be invariant with respect to $\theta$ and based on this assumption, we extrapolated our results to higher $\theta$ values. It is important to specify here that for AA/EG molecules, we report the average cumulative adsorption free energy with respect to the number adsorbed AA/EG molecules. Hence to compare cobalt free energies with that of AA and EG we will extract similar data from the incremental free energies of Ref. ${ }^{6}$ according the numerical methods described in supplementary materials S4.

\subsection{Energy calculations}

The following assumptions were made for the calculation of the adsorption free energies that are discussed in this work:

- The vibrational contributions to the adsorption energy compensate between the reactants and the products.

- The molecules and the cobalt complex lose $1 / 3$ of their rotational and translational degrees of freedom upon transfer from vacuum to water. 
- The translational and rotational degrees of freedom of the molecules and cobalt complex in the liquid phase are converted into bound motions after adsorption.

The adsorption free energies of the organic molecules and the cobalt complex were calculated as described in S3 section of the supplementary electronic materials. The electronic energies $\left(E^{e l}\right.$ terms in S3) were calculated from geometry optimizations using periodic density functional calculations with the VASP code ${ }^{42-45}$ and the Generalized Gradient Approximation PBE functional (GGA-PBE) ${ }^{46,47}$ within the projected augmented-wave (PAW) method ${ }^{48,49}$.The solvation effects for our systems in the liquid phase (Figures 2 and 6) were treated with an implicit solvation model (we used the dielectric constant of water) that is implemented in the VASPsol software ${ }^{50}$. Dispersion corrections were included in our calculations through the Grimme-D2 method ${ }^{51}$. For all our simulated systems, the geometry were considered to be optimized when the ionic forces were smaller than $0.02 \mathrm{eV} / \AA$ and spin polarized calculations were performed for the systems with cobalt. For a rapid screening of the 1000 initial configurations in section 2.1 .1 we used an energy cutoff of $300 \mathrm{eV}$ for the plane-wave basis set and a normal precision. Later on a high precision and a cutoff of $400 \mathrm{eV}$ were used for the calculations in sections 2.1.2 and 2.1.3. Integration over the Brillouin zone was done in a set of k-points provided by the Monkhorst-Pack algorithm ${ }^{52}$ within a grid of $0.02 \AA^{-1}$ fineness.

\section{Results}

\subsection{Adsorption at high surface coverage}

\subsubsection{Energetics}

First of all, we compare energy values obtained with calculations using the small cell (1x1) representation -the unit cell used for a rapid sampling of the potential energy surface 
(PES)- with those obtained with larger slabs -larger than the unit cell- at the same surface adsorbate coverage. Adsorption energy values of AA and EG molecules are reported in Figure 6. From these data the most favorable adsorption configurations (lowest $\Delta \mathrm{G}$ ) were refined using larger simulations cells as explained before, and the refined structures and energies are reported in Figures 7 and 8. The free energy data indicate a non-systematic trend regarding the surface size: the energy values are slightly smaller for AA in the large systems for both surfaces, and for EG on the larger (110) surface. However EG free energy values are slightly higher on the larger (100) surface, compared to the smaller systems. These fluctuations do not exceed $10 \mathrm{~kJ} / \mathrm{mol}$, and can be attributed to the $\mathrm{H}$-bonds stretching or rather, to a small reorganization of $\mathrm{H}$-bonds on the $\gamma$-alumina surfaces. In the following sections of this manuscript, the free energy values that are presented and discussed, as well as the adsorption configurations, are those obtained in the large cells.

(a)

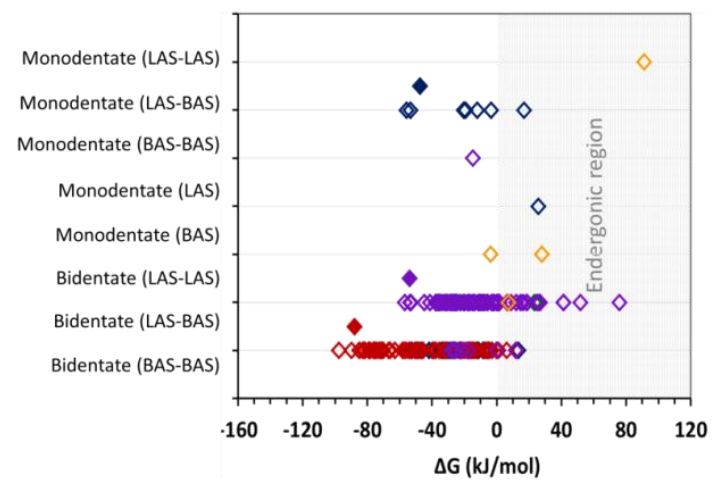

(c)

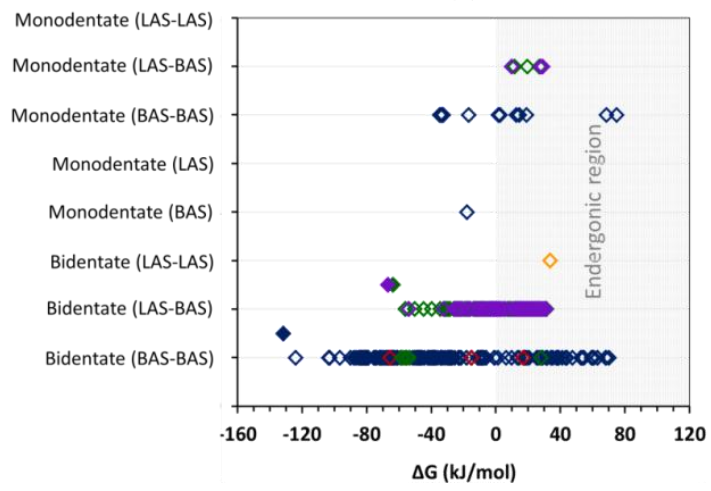

(b)

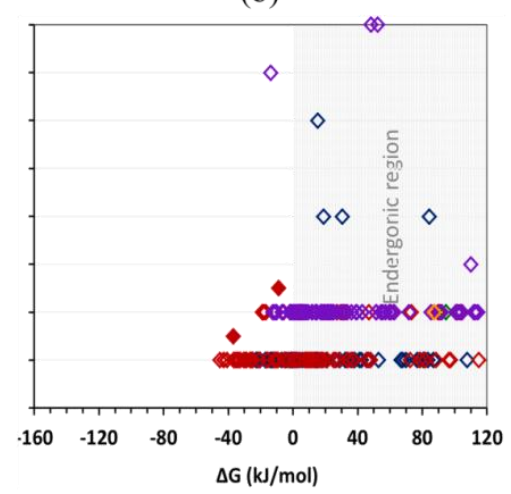

(d)

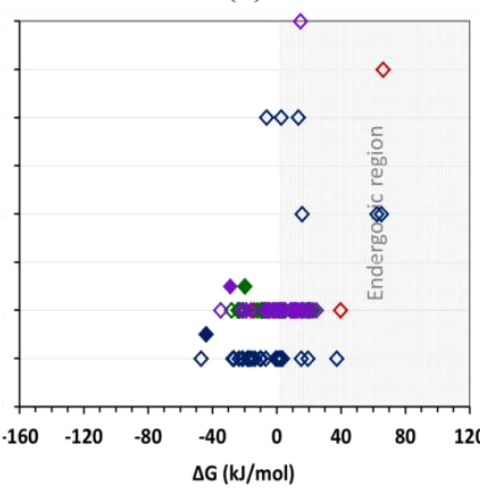

$D$ (Dissociative)

ND (Non Dissociative)

$\triangle N D$

$\diamond \mathrm{DD}\left(-\mathrm{H}_{2} \mathrm{O}\right)$

$\diamond \mathrm{D}\left(-\mathrm{H}_{2} \mathrm{O}\right)$

$\triangle D\left(-2 \mathrm{H}_{2} \mathrm{O}\right)$

Figure 6. Adsorption free energy for the various adsorption modes at high coverage (calculations done in the small cells): AA on the (100) surface (a), AA on the (110) surface 
(b), EG on the (100) surface (c) and EG on the (110) surface (d). The filled symbols represent the free energy values of the most favorable configurations refined in the large cells.

When adsorbed, AA binds more strongly on the (100) surface than on the (110) surface as shown by the most exergonic $\Delta \mathrm{G}$ values (for each plot in Figures $6 \mathrm{a}$ and $6 \mathrm{~b}$ ). The most favorable adsorption configuration on the (100) surface has a free energy value that is more than twice its equivalent on the (110) surface $\left(\Delta \mathrm{G}_{(100)} \approx-88 \mathrm{~kJ} / \mathrm{mol}\right.$ while $\Delta \mathrm{G}_{(110)} \approx-37$ $\mathrm{kJ} / \mathrm{mol}$ ). Moreover, the two other favorable adsorption configurations on the (100) surface have free energy values that are also more exergonic than those for any of the most favorable adsorption modes on the (110) surface (Figures $6 \mathrm{a}$ and $6 \mathrm{~b}$ ). As for EG, similarly to AA, the three most favorable adsorption configurations of this molecule on the (100) surface exhibit more negative $\Delta \mathrm{G}$ values than those on the (110) surface (Figures $6 \mathrm{c}$ and $6 \mathrm{~d}$ ). Moreover the most favorable adsorption configuration of EG on the (100) surface has a free energy value almost three times higher than his counterpart on the (110) surface $\left(\Delta \mathrm{G}_{(100)} \approx-132 \mathrm{~kJ} / \mathrm{mol}\right.$ while $\left.\Delta \mathrm{G}_{(110)} \approx-47 \mathrm{~kJ} / \mathrm{mol}\right)$. It is clear from these observations that AA and EG molecules have a significantly higher affinity towards the (100) surface in comparison with the (110) surface. Moreover the free energy differences between the two surfaces are greater for EG than for AA.

\subsubsection{Structural features of the adsorption configurations}

a) Adsorption modes

For both surfaces, the most favorable configurations of AA belong to the bidentate BAS-BAS adsorption mode, here denoted asas $\mathrm{AA}_{(100)}^{1}$ and $\mathrm{AA}_{(110)}^{1}$ (Figures $7 \mathrm{~b}$ and $8 \mathrm{~b}$ ). The oxygen atoms of AA can also form a iono-covalent bond with Al sites on both surfaces: the corresponding adsorption configurations belong to the bidentate LAS-BAS adsorption mode, 
here denoted as $\mathrm{AA}_{(100)}^{2}$ and $\mathrm{AA}_{(110)}^{2}$ (Figures $7 \mathrm{~b}$ and $8 \mathrm{~b}$ ). This requires not only the dissociation of the AA molecule, but also the removal of one $\mathrm{H}_{2} \mathrm{O}$ molecule from the (100) surface to make available one $\mathrm{Al}_{\mathrm{V}}$ site for the anchoring of AA. On the (110) surface, AA can directly bind the $\mathrm{Al}_{\mathrm{IV}}$ site without water removal (Figure $8 \mathrm{~b}$ ). $\mathrm{AA}_{(100)}^{2}$ and $\mathrm{AA}_{(110)}^{2}$ are clearly less favorable than $\mathrm{AA}_{(100)}^{1}$ and $\mathrm{AA}_{(110)}^{1}$, respectively (Figures $7 \mathrm{~b}$ and $8 \mathrm{~b}$ ). On the (100) surface, a third favorable adsorption configuration, called $\mathrm{AA}_{(100)}^{3}$, belongs to the monodentate BAS-BAS adsorption mode (Figure 7b) and is energetically very close to $\mathrm{AA}_{(100)}^{2}(-47 \mathrm{~kJ} / \mathrm{mol} \mathrm{vs}-54 \mathrm{~kJ} / \mathrm{mol})$. In this case the AA molecule does not dissociate upon adsorption and binds directly to the surface through hydrogen bonds. 
(a)
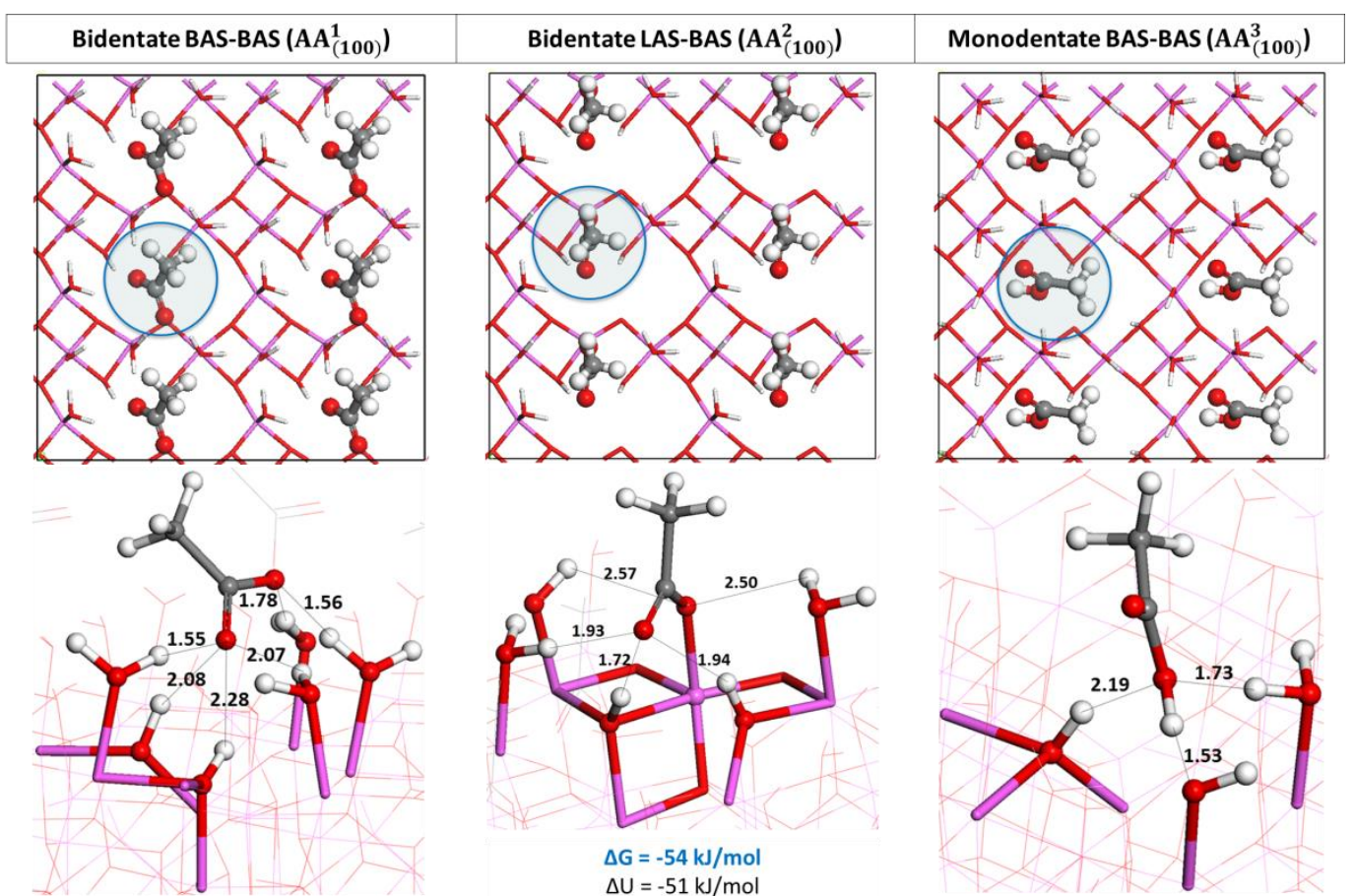

(b)
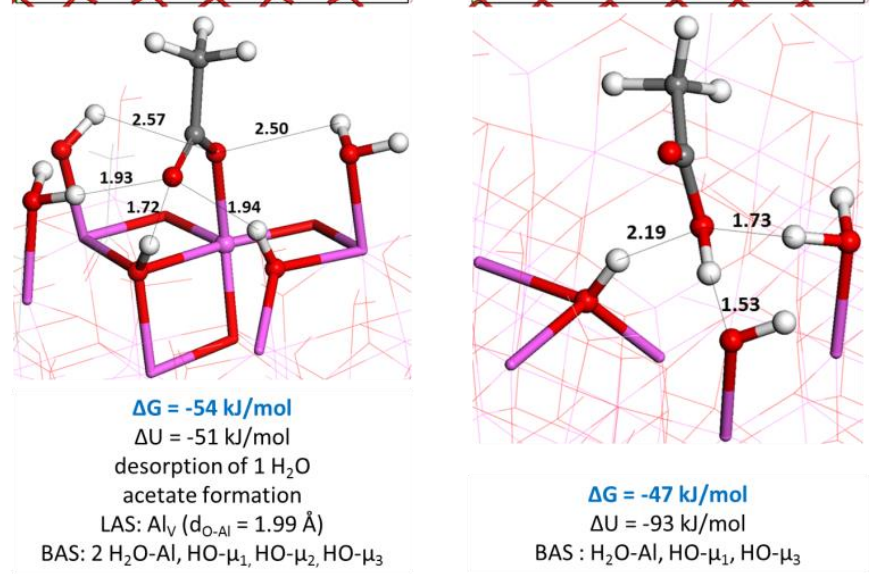

$\Delta \mathrm{G}=-88 \mathrm{~kJ} / \mathrm{mol}$

$\Delta \mathrm{U}=-133 \mathrm{~kJ} / \mathrm{mol}$

acetate formation

BAS : $4 \mathrm{H}_{2} \mathrm{O}-\mathrm{Al}$, $\mathrm{HO}-\mu_{2}, \mathrm{HO}-\mu_{3}$

BAS: $2 \mathrm{H}_{2} \mathrm{O}-\mathrm{Al}, \mathrm{HO}-\mu_{1}, \mathrm{HO}-\mu_{2}, \mathrm{HO}-\mu_{3}$

$\begin{aligned} \Delta \mathrm{G} & =-47 \mathrm{~kJ} / \mathrm{mol} \\ \Delta \mathrm{U} & =-93 \mathrm{~kJ} / \mathrm{mol}\end{aligned}$ BAS : $\mathrm{H}_{2} \mathrm{O}-\mathrm{Al}, \mathrm{HO}-\mu_{1}, \mathrm{HO}-\mu_{3}$

(c)

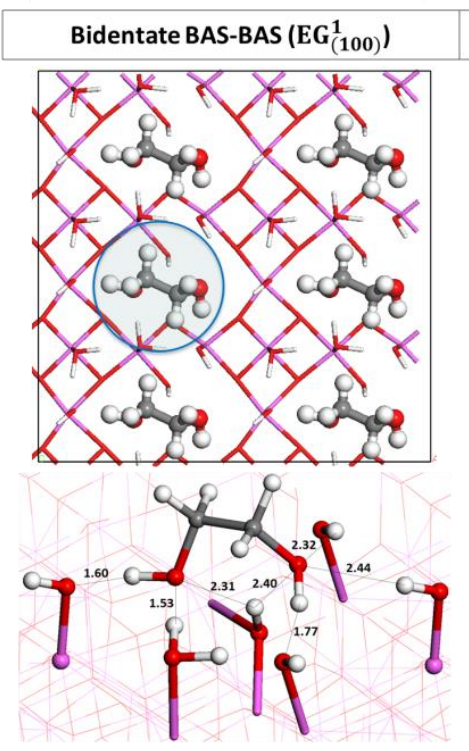

$$
\begin{gathered}
\Delta \mathrm{G}=-132 \mathrm{~kJ} / \mathrm{mol} \\
\Delta \mathrm{U}=-177 \mathrm{~kJ} / \mathrm{mol} \\
\text { BAS : } \mathrm{H}_{2} \mathrm{O}-\mathrm{Al}, 4 \mathrm{HO}-\mu_{1}, \mathrm{HO}-\mu_{2}
\end{gathered}
$$

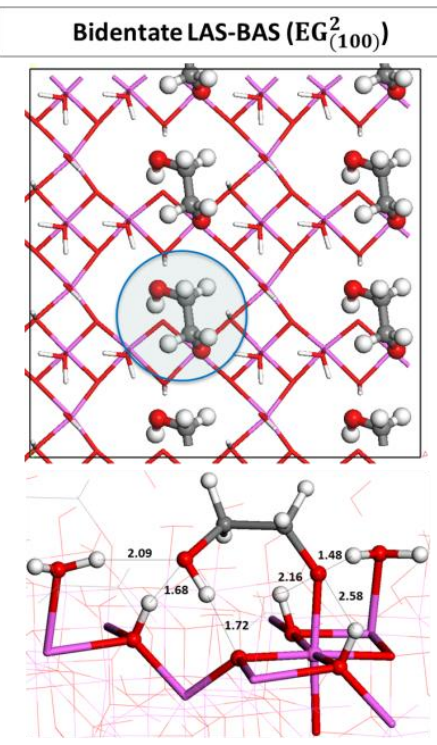

$\Delta \mathrm{G}=-67 \mathrm{~kJ} / \mathrm{mol}$

$\Delta \mathrm{U}=-64 \mathrm{~kJ} / \mathrm{mol}$

desorption of $1 \mathrm{H}_{2} \mathrm{O}$

glycolate formation

LAS : $\mathrm{Al}_{\mathrm{VI}}\left(\mathrm{d}_{\mathrm{O}}=1.95 \AA\right)$

BAS : $2 \mathrm{H}_{2} \mathrm{O}-\mathrm{Al}, 3 \mathrm{HO}-\mu_{3}, \mathrm{O}-\mu_{3}$
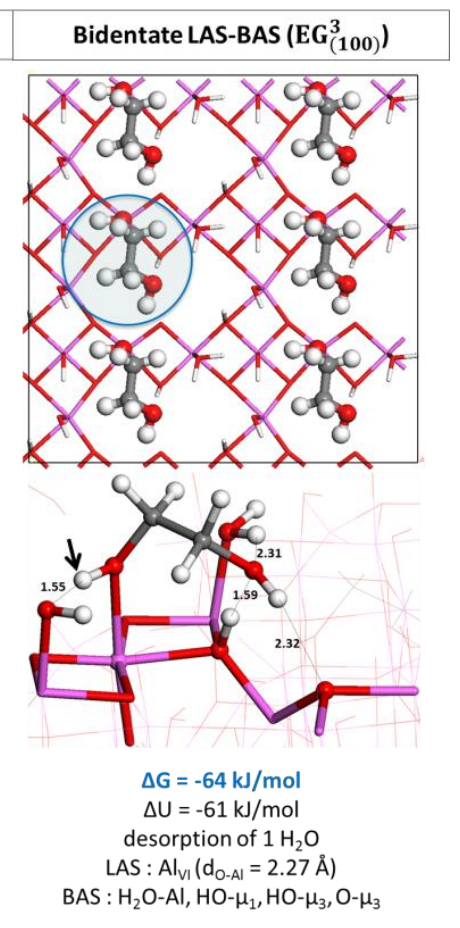

Figure 7. Molecular views of the most favorable adsorption configurations of AA and EG on the (100) surface in the large cells at $\theta_{(100)}=2.15$ molecules $/ \mathrm{nm}^{2}$. Subfigures (a) and (c) are respectively the top views of AA molecules and EG molecules on the surface. The blue circles represent a hypothetic van der Waals sphere around the molecules. The surface interacting sites around one AA molecule and one EG molecule are highlighted in (b) and (d). 
(a)

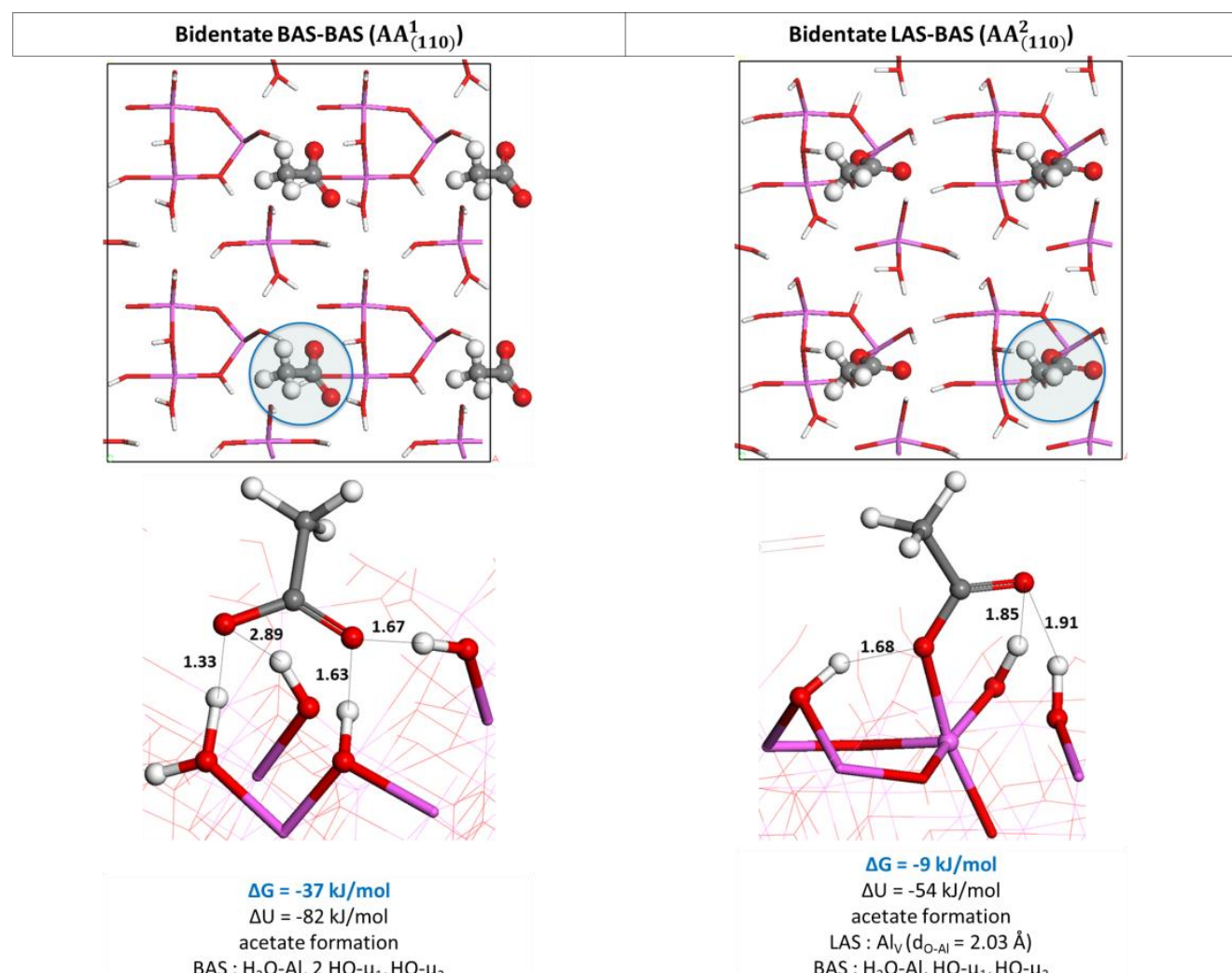

(b)

(c)
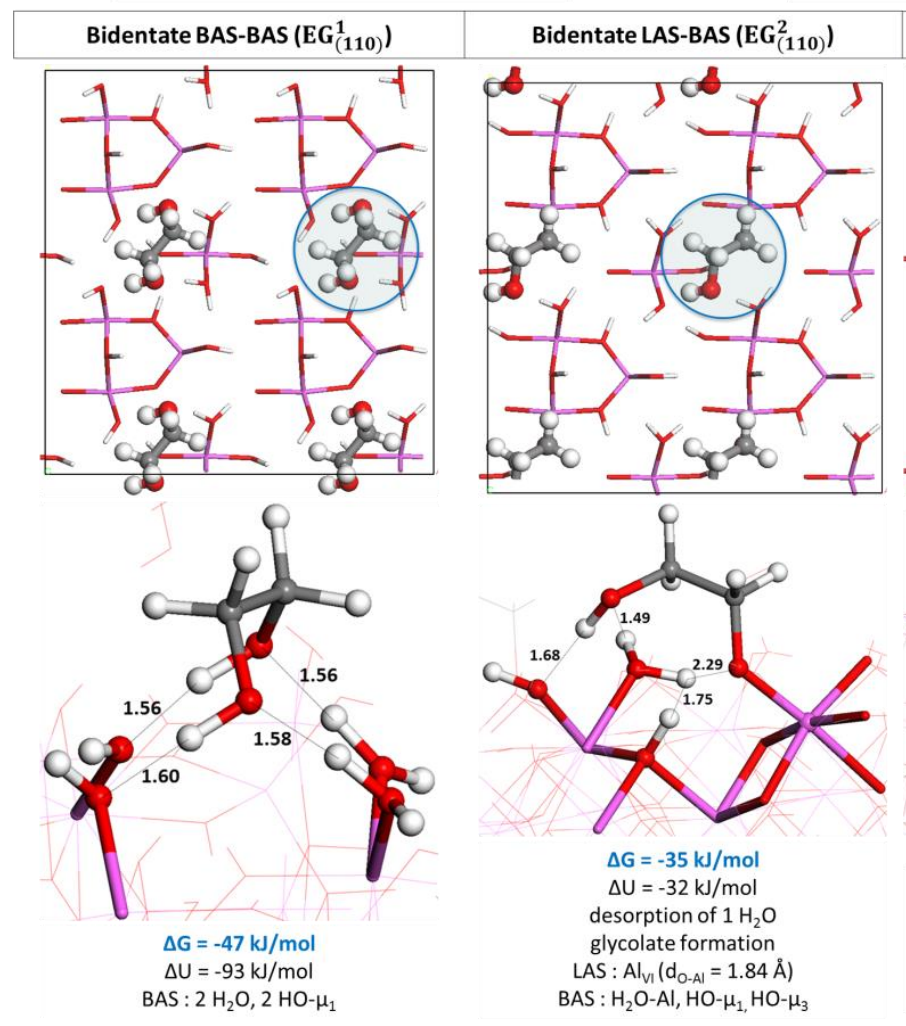

Bidentate LAS-BAS $\left(\mathbf{E G}_{(\mathbf{1 1 0})}^{3}\right)$

(d)
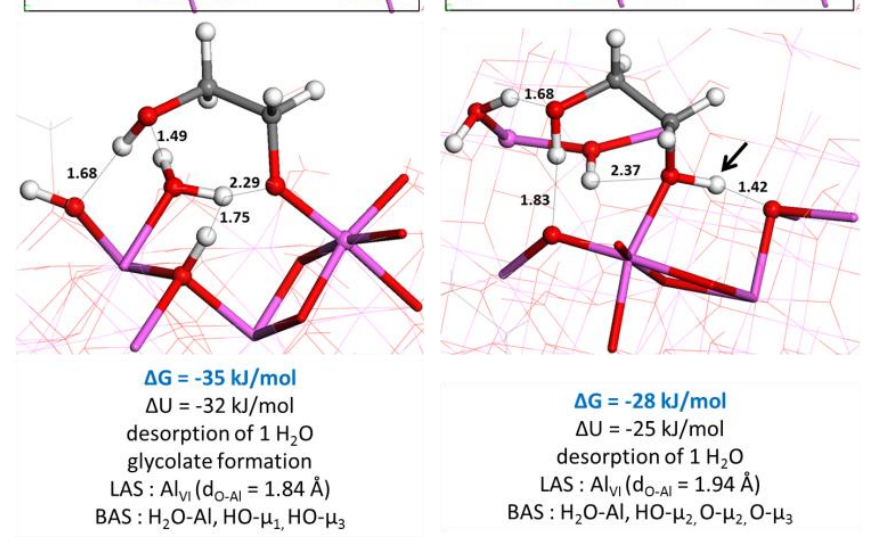

Figure 8. Molecular views of the most favorable adsorption configurations of AA and EG on the (110) surface in the large cells at $\theta_{(110)}=1.49 \mathrm{molecules} / \mathrm{nm}^{2}$. Subfigures (a) and (c) are respectively the top views of AA molecules and EG molecules on the surface. The blue circles represent a hypothetic van der Waals sphere around the molecules. The surface interacting sites around one AA molecule and one EG molecule are highlighted in (b) and (d). 
Similarly to AA, EG binds more strongly to the (100) surface compared to the (110) one, as revealed by the most negative $\Delta \mathrm{G}$ values in Figures $6 \mathrm{c}$ and $6 \mathrm{~d}$. It also appears from these figures that the EG molecule prefers in most cases to form hydrogen bonds with both surfaces as its most stable configurations $\left(\mathrm{EG}_{(100)}^{1}\right.$ and $\left.\mathrm{EG}_{(110)}^{1}\right)$ belong to the bidentate BASBAS mode (see Figures $7 \mathrm{~d}$ and $8 \mathrm{~d}$ ). Unlike AA, no proton dissociation is involved in the adsorption process leading to $\mathrm{EG}_{(100)}^{1}$ and $\mathrm{EG}_{(110)}^{1}$ configurations. Furthermore, two other favorable adsorption configurations are identified for each surface, all belonging to the bidentate LAS-BAS mode (Figures $7 \mathrm{~d}$ and $8 \mathrm{~d}$ ). In both cases EG forms a covalent bond with the surface and a $\mathrm{H}_{2} \mathrm{O}$ molecule is released. It is interesting to see that EG can form such a iono-covalent Al-O bond with the (100) and (110) surfaces of $\gamma$-alumina following either a dissociative mode (see $\mathrm{EG}_{(100)}^{2}$ in Figure $8 \mathrm{~d}$ and $\mathrm{EG}_{(110)}^{2}$ in Figure 8d) or a non-dissociative one (see $\mathrm{EG}_{(100)}^{3}$ in Figure $7 \mathrm{~d}^{3}$ and $\mathrm{EG}_{(110)}^{3}$ in Figure $8 \mathrm{~d}$ ). Our energetic analysis shows that these two modes, where EG forms iono-covalent Al-O bond, are twice as less favored than the BAS-BAS EG ${ }^{1}$ mode on the (100) surface, whereas on the (110) the three modes are closer in energy. This also means that the Al site on the (100) prefers to remain coordinated to one water molecule rather than to EG. This result is consistent with FT-IR ${ }^{28}$ and Sum Frequency Generation $(\mathrm{SFG})^{53}$ showing that EG interact predominantly through hydrogen bonds on alumina surfaces. in presence of water at RT. In the present study, the non-negligible hydroxyl groups present on the alumina surfaces at $\mathrm{T}=298 \mathrm{~K}$ explains also this trend. Moreover, we show that this trend may be more pronounced on the (100) surface than on the (110).

b) Analysis of the hydrogen and/or iono-covalent bonds involved 
When analyzing the nature and the number of the interacting hydroxyl groups for the $\mathrm{AA}_{(100)}^{1}, \mathrm{AA}_{(110)}^{1}, \mathrm{EG}_{(100)}^{1}$ and $\mathrm{EG}_{(110)}^{1}$ configurations, we count 6 and 4 interacting hydroxyls for each molecule respectively on the (100) surface and the (110) surface. For AA, these interacting hydroxyls are $4 \mathrm{H}_{2} \mathrm{O}-\mu_{1}, 1 \mathrm{HO}-\mu_{2}$, and $1 \mathrm{HO}-\mu_{3}$ surface groups on the (100) surface (Figure 7b) and $1 \mathrm{H}_{2} \mathrm{O}-\mu_{1}, 2 \mathrm{HO}-\mu_{1}$, and $1 \mathrm{HO}-\mu_{2}$ surface groups on the (110) surface (Figure 8b). Considering this analysis, the (100) surface involves a higher number of H-bonds (hydrogen bonds are defined according to IUPAC recommendations of $2011^{54}$; we do not consider any hydrogen bond longer than $3.0 \AA$ ) and also surface hydroxyls such as $1 \mathrm{HO}-\mu_{3}$ and $\mathrm{H}_{2} \mathrm{O}-\mu_{1}$ which are stronger $\mathrm{H}$-bond donors (ie more acidic) than on the (110) surface (with $\left.2 \mathrm{HO}-\mu_{1}\right)$, this may explain the more exergonic $\Delta \mathrm{G}$ values found on the (100) surface. For EG, we identify $1 \mathrm{H}_{2} \mathrm{O}-\mu_{1}, 4 \mathrm{HO}-\mu_{1}$, and $1 \mathrm{HO}-\mu_{2}$ surface groups on the (100) surface (Figure 8d) and $2 \mathrm{H}_{2} \mathrm{O}-\mu_{1}$ and $2 \mathrm{HO}-\mu_{1}$ surface groups on the (110) surface (Figure $8 \mathrm{~d}$ ).

For the $\mathrm{AA}_{(100)}^{3}$ configuration (Figure $7 \mathrm{~b}$ ), for which no proton dissociation is involved in the adsorption process and where AA is also interacting with the surface only through hydrogen bonds, there are 3 interacting surface groups: $\mathrm{H}_{2} \mathrm{O}-\mu_{1}, \mathrm{HO}-\mu_{1}$, and $\mathrm{HO}-\mu_{3}$. As previously described, the $\mathrm{AA}_{(100)}^{2}$ and $\mathrm{AA}_{(110)}^{2}$ configurations reveal that the molecules interact through iono-covalent $\mathrm{O}-\mathrm{Al}$ bond formed between $\mathrm{AA}$ and the $\mathrm{Al}_{\mathrm{V}}$ site of the $(100)$ surface $\left(\mathrm{d}_{\mathrm{O}-\mathrm{Al}}=1.99 \AA\right.$, Figure $\left.7 \mathrm{~b}\right)$ and the $\mathrm{Al}_{\mathrm{IV}}$ site of the $(110)$ surface $\left(\mathrm{d}_{\mathrm{O}-\mathrm{Al}}=2.03 \AA\right.$, Figure 8b). Moreover, both $\mathrm{AA}^{2}$ structures interact with 5 sites on the (100) surface $\left(2 \mathrm{H}_{2} \mathrm{O}\right.$ $\mu_{1}, 1 \mathrm{HO}-\mu_{1}, 1 \mathrm{HO}-\mu_{2}$, and $\left.1 \mathrm{HO}-\mu_{3}\right)$, and only 3 sites on the (110) surface $\left(1 \mathrm{H}_{2} \mathrm{O}-\mu_{1}, 1 \mathrm{HO}-\right.$ $\mu_{1}$, and $\left.1 \mathrm{HO}-\mu_{2}\right)$. As for $\mathrm{AA}^{1}$, the nature and number of $\mathrm{H}$-bond donors involved explain easily the energetic trends. Moreover, the Al-O bond length is slightly shorter on the (100) which may reinforce the interaction on this surface. In the $\mathrm{EG}_{(100)}^{2}$ configuration, the molecule interacts with $2 \mathrm{H}_{2} \mathrm{O}-\mathrm{Al}, 3 \mathrm{HO}-\mu_{3}$ and $1 \mathrm{O}-\mu_{3}$ groups on the (100) surface with a covalent $\mathrm{O}-$ 
Al bond length of $\mathrm{d}_{\mathrm{O}-\mathrm{Al}}=1.95 \AA$ (Figure $7 \mathrm{~d}$ ). For the analogous $\mathrm{EG}_{(110)}^{2}$ configuration on the (110) surface, only one $\mathrm{H}_{2} \mathrm{O}-\mu_{1}$, one $\mathrm{HO}-\mu_{1}$, one $\mathrm{HO}-\mu_{3} \mathrm{H}$-donor and one $\mathrm{O}-\mu_{3}$ bond acceptor are the surface interacting sites and $\mathrm{d}_{\mathrm{O}-\mathrm{Al}}=1.84 \AA$ (Figure $7 \mathrm{~d}$ ). Unlike AA, one possible mode (although less energetically favorable) of EG is the non-dissociative bidentate LAS-BAS adsorption found on the two studied surfaces $\left(\mathrm{EG}_{(100)}^{3}\right.$ and $\left.\mathrm{EG}_{(110)}^{3}\right)$. The $\mathrm{EG}_{(100)}^{3}$ and $\mathrm{EG}_{(110)}^{3}$ configurations involve 4 interacting surface groups on the (100) surface $\left(\mathrm{H}_{2} \mathrm{O}-\mathrm{Al}, \mathrm{HO}-\mu_{1}, \mathrm{HO}-\mu_{3}\right.$ and $\mathrm{O}-\mu_{3}$, see Figure $\left.7 \mathrm{~d}\right)$, and on the (110) surface $\left(\mathrm{H}_{2} \mathrm{O}-\mathrm{Al}, \mathrm{HO}-\mu_{2}\right.$, $\mathrm{O}-\mu_{2}$ and $\mathrm{O}-\mu_{3}$, Figure $8 \mathrm{~d}$ ). The small energetic differences appearing between $\mathrm{EG}_{(100)}^{2}$ and $\mathrm{EG}_{(100)}^{3}\left(\Delta \Delta \mathrm{G}_{(100)}=3 \mathrm{~kJ} / \mathrm{mol}\right.$, see Figure 6d) and between $\mathrm{EG}_{(110)}^{2}$ and $\mathrm{EG}_{(110)}^{3}$ $\left(\Delta \Delta \mathrm{G}_{(110)}=7 \mathrm{~kJ} / \mathrm{mol}\right.$, see Figure $\left.7 \mathrm{~d}\right)$, can be attributed to the $\mathrm{O}-\mathrm{Al}$ covalent bond interactions of $\mathrm{EG}_{(100)}^{3}$ and $\mathrm{EG}_{(110)}^{3}$ that are weaker than those for the $\mathrm{EG}_{(100)}^{2}$ and $\mathrm{EG}_{(110)}^{2}$ configurations. Moreover these tiny energy differences may also indicate that the protons marked by an arrow in Figures $6 \mathrm{~d}, 7 \mathrm{~d}, \mathrm{~S} 2.2 \mathrm{~d}$ and $\mathrm{S} 2.3 \mathrm{~d}$ are prone to dissociation, and this proton dissociation may strengthen the covalent $\mathrm{O}-\mathrm{Al}$ bond interaction and yield $\mathrm{EG}_{(100)}^{3}$ and $\mathrm{EG}_{(110)}^{3}$ configurations as stable as those in $\mathrm{EG}_{(100)}^{2}$ and $\mathrm{EG}_{(110)}^{2}$.

\subsubsection{Effect of the alumina facet on the adsorption structures and energies}

We now focus on the interaction of AA and EG with different surface facets. Hereafter, surface $\mathrm{H}_{2} \mathrm{O}-\mathrm{Al}$ and $\mathrm{HO}-\mu_{1}$ groups above the average surface plane (see figure $1 \mathrm{~b}$ ) will be referred to as external groups while those within the average plan will be considered as internal groups. This distinction is not only motivated from the relative position of this hydroxo groups but also from the fact that the former ones have been incorporated to the surface through water adsorption, whereas the latter ones involve surface oxygen atoms from the bulk material ${ }^{32,40}$. When looking at the local environment around AA and EG for the $\mathrm{AA}_{(100)}^{1}, \mathrm{AA}_{(100)}^{3}, \mathrm{AA}_{(110)}^{1}, \mathrm{EG}_{(100)}^{1}$ and $\mathrm{EG}_{(110)}^{1}$ configurations (Figures $7 \mathrm{~b}, 7 \mathrm{~d}, 8 \mathrm{~b}$, and 8d) 
we see that the external $\mathrm{H}_{2} \mathrm{O}-\mathrm{Al}$ and $\mathrm{HO}-\mu_{1}$ groups interact with $\mathrm{AA}$ and $\mathrm{EG}$ molecules on the (100) and (110) surfaces while the internal $\mathrm{HO}-\mu_{2}$, and $\mathrm{HO}-\mu_{3}$ groups are found in the case of the (100) surface only. Note that the HO- $\mu_{2}$ group interacting with AA on the (110) surface is an external surface group, according to our definition in Figure 1b). It is clear from these observations that the strength of molecule-surface interactions and the corresponding free energy differences that we found for both molecules on each of the two surfaces can be attributed not only to the nature and number of interacting sites, but also to the surface topology or roughness. On the (100) surface AA and EG molecules are able to insert in the surface cavities (Figures 1a and 7a and 7c) and to bind to the hydroxyl nests surrounding these cavities. If we evaluate the position of EG with respect to the average surface plane: it is clearly shifted downwards on the (100) surface (Figure S2.1b) with respect to the (110) surface (Figure S2.1d), and this also enhances significantly the molecule-surface interaction.

On the (110) orientation, surface roughness (Figure 1a) prevents the AA and EG molecules to closely contact the surface such that there is a smaller number of interacting hydroxyls accessible to the molecules (Figure 8 and Figure S2.1c). A similar effect was invoked by the study of xylitol adsorption on boehmite surfaces ${ }^{55}$, where the presence of such hydroxyl nests play a key role in stabilizing the xylitol on the surfaces. Therefore, the stabilization may depend both on the type of the facets and on the corresponding topology of the hydroxyl cavities.

The $\mathrm{AA}_{(100)}^{2}, \mathrm{AA}_{(110)}^{2}, \mathrm{EG}_{(100)}^{2}, \mathrm{EG}_{(110)}^{2}, \mathrm{EG}_{(100)}^{3}$, and $\mathrm{EG}_{(110)}^{3}$ configurations are characterized by the $\mathrm{O}-\mathrm{Al}$ covalent bond between the molecule and the surface. We recall that in the $\mathrm{AA}_{(110)}^{2}$ configuration there is no $\mathrm{H}_{2} \mathrm{O}$ desorption involved, as it is the case for all other configurations in the list above. The formation of a covalent bonds may provide a large contribution in stabilizing molecule adsorption on the surfaces. However this is only true if the steric hindrance of the molecule and the perturbation of the H-bond network remain 
moderate. This can be ensured by desorbing a $\mathrm{H}_{2} \mathrm{O}$ molecule from the surface. Besides, when this $\mathrm{H}_{2} \mathrm{O}$ is taken out from the (100) surface, AA and $\mathrm{EG}$ in the $\mathrm{AA}_{(100)}^{2}, \mathrm{EG}_{(100)}^{2}$, and $\mathrm{EG}_{(100)}^{3}$ configurations have more room to interact with internal $\mathrm{HO}-\mu_{3}$ and even $\mathrm{O}-\mu_{3}$ surface groups (Figures $7 \mathrm{~b}$ and $7 \mathrm{~d}$ ). Interestingly on the (110) surface, the water molecule is so strongly held on the $\mathrm{Al}_{\text {IV }}$ site that the energy cost for breaking a $\mathrm{H}_{2} \mathrm{O}-\mathrm{Al}$ bond (and the $\mathrm{H}$ bonds connections with it) on the surface is not compensated by the formation of the new OAl bond between AA and the (110) surface. Hence the only way to become exergonic (-9 $\mathrm{kJ} / \mathrm{mol}$ ) upon adsorption of $\mathrm{AA}$ is to keep a $\mathrm{H}_{2} \mathrm{O}$ molecule on the $\mathrm{Al}_{\mathrm{IV}}$ site of the (110) surface. In fact, when the $\mathrm{H}_{2} \mathrm{O}$ molecule is removed from the $\mathrm{Al}_{\mathrm{IV}}$ before the adsorption of AA, the adsorption free energy has a maximum value of $+4 \mathrm{~kJ} / \mathrm{mol}$. By contrast, EG bonds with the (110) orientation are strong enough to fully compensate the energy cost needed to take out $1 \mathrm{H}_{2} \mathrm{O}$ from the surface, so that more energy is gained in the process: $-9 \mathrm{~kJ} / \mathrm{mol}$ for $\mathrm{AA}^{2}$ (Figure $8 \mathrm{~b}$ ) compared to -28 for $\mathrm{EG}^{2}$ or $-35 \mathrm{~kJ} / \mathrm{mol}$ for $\mathrm{EG}^{3}$ (see Figure $8 \mathrm{~d}$ ). One should note that in the $\mathrm{EG}^{2}$ and $\mathrm{EG}^{3}$ configurations the $\mathrm{EG}$ molecule is covalently bonded to the $\mathrm{Al}_{\mathrm{VI}}(\mathrm{II})$ and $\mathrm{Al}_{\mathrm{VI}}(\mathrm{III})$ sites on the (110) surface (Figure 1a), respectively. This situation can only happen if a water molecule is removed from these sites. This observation clearly indicates that for a given surface, the nature of the adsorbed molecule significantly affects molecule-surface interactions.

\subsubsection{Influence of the molecule on the adsorption energies and structures}

Figures 7-8 show that both surfaces have a higher affinity for EG than for AA, and the energetic trends between AA and EG also vary according to the adsorption mode.

According to Figures $7 \mathrm{~b}$ and $7 \mathrm{~d}$, the free energy change for the $\mathrm{EG}^{1}{ }_{(100)}$ structure is more exothermic than the one for the $\mathrm{AA}_{(100)}^{1}$ structure by $44 \mathrm{~kJ} / \mathrm{mol}$, while the difference between $\mathrm{EG}_{(110)}^{1}$ and $\mathrm{AA}_{(110)}^{1}$ structures is $10 \mathrm{~kJ} / \mathrm{mol}$ (Figures $9 \mathrm{~b}$ and $9 \mathrm{~d}$ ). The calculated free 
energy values indicate that, when only hydrogen bonds connect the molecule to the surface, AA and EG interacts very similarly with the (110) surface. This assertion is reinforced by the same number of hydrogen bonds (4 in each case) that relates both molecules to the (110) surface (Figures 8b and 8d). Oppositely, on the (100) surface the bidentate BAS-BAS configurations of AA and EG have respectively 6 (Figure 7b) and 7 (Figure 7d) hydrogen bonds with the surface. Their corresponding free energy values indicate that EG binds more strongly than AA on the (100) surface. First, the slightly longer and flexible O-C-C-O chain of EG is more suitable, compared to AA, for occupying two (100) surface cavities as discussed above so that it provides hydrogen bonds with almost all the surface hydroxyl groups (external and internal) found around those cavities. EG is thus more prone to be oriented in a parallel position with a rather symmetric distribution of $\mathrm{H}$-bonds involving the two $\mathrm{OH}$ groups of EG, whereas AA is tilted with a non-symmetric distribution of H-bonds on the two $\mathrm{O}$ atoms (Figure S2.1). Moreover, according to the distributions and orientations of the two molecules on the (100) surface (Figures 7a, and 7c) and the (110) surface (Figures 8a, and $8 \mathrm{c}$ ), molecule-molecule interactions are suspected to be stronger on the former surface than on the later. The molecule-molecule and molecule-surface stabilizing dispersion forces contribution will favor EG adsorption compared to AA, and this effect seems to be more significant on the (100) surface than on the (110) surface. All these parameters explain the 44 $\mathrm{kJ} / \mathrm{mol}$ energy difference between AA and EG on the (100) surface.

On the (110) surface, due to the smaller energy difference between AA and EG, it is far more difficult to extract one unambiguous parameter differentiating the behavior of the two molecules.

When covalent bonds are formed between the molecules and the surfaces, adsorption free energies of both molecules differ by $\Delta \mathrm{G}\left(\mathrm{AA}_{(100)}^{2}\right)-\Delta \mathrm{G}\left(\mathrm{EG}_{(100)}^{2}\right)=13 \mathrm{~kJ} / \mathrm{mol}$ on the $(100)$ surface, where EG has 6 hydrogen bond connections and one $\mathrm{O}-\mathrm{Al}$ covalent bond length of 
$1.95 \AA$ (Figure 7d) while AA has 5 hydrogen bonds and one slightly longer O-Al bond distance ( $1.99 \AA$ ) (Figure 7b). On the (110) surface, $\Delta \mathrm{G}\left(\mathrm{AA}_{(110)}^{2}\right)-\Delta \mathrm{G}\left(\mathrm{EG}_{(110)}^{2}\right)$ is about +26 $\mathrm{kJ} / \mathrm{mol}$. However, as mentioned above, the adsorption process of $\mathrm{AA}^{2}$ does not involve water removal, so there is no entropic compensation as it is the case for EG. Thus, although $\Delta \mathrm{U}\left(\mathrm{AA}_{(110)}^{2}\right)$ is more exothermic than $\Delta \mathrm{U}\left(\mathrm{EG}_{(110)}^{2}\right.$, it becomes the reverse for the $\Delta \mathrm{G}$ values due to entropic effect. Hence, when a covalent bond is formed with the surface, EG adsorption free energies on both surfaces are stronger compared to AA, and this effect is more pronounced on the (110) surface compared to the (100) surface due to entropic effect of water. Moreover EG being more flexible than AA, the molecule is able to deform its O-C-CO backbone easily in order to maximize the interactions with the surface. EG exhibits many flat lying configurations where its $\mathrm{C}-\mathrm{C}$ bond is oriented parallel to the surface, whereas AA is often oriented perpendicularly or tilted with respect to the surface.

\subsection{Effect of surface coverage}

To better control the optimum surface loadings to be used during the impregnation step of the $\gamma$-alumina surfaces by organic additives, it is important to know how the number of molecules adsorbed on the surface affects the structure and energy of adsorbed configurations. The results presented and discussed above were obtained at surface coverage values of $\theta_{(100)}$ $=2.15$ molecules $/ \mathrm{nm}^{2}$ and $\theta_{(110)}=1.49$ molecules $/ \mathrm{nm}^{2}$ ( the highest values considered for both surfaces in this work). In what follows, we extend to lower surface coverage values (prepared as explained in section 2.1.2).

\subsection{1 (100) surface}

Acetic acid 
The variation of the adsorption free energy as a function of the surface coverage value is plotted in Figure 9a for AA on the (100) surface. For the configurations and $\theta$ values considered here, the adsorption of AA molecules on the (100) surface is always an exergonic reaction and the energy is the most exergonic for the lowest $\theta$ value. However, no clear trend can be deduced regarding the variation of the free energy with respect to surface coverage. In any case, the order of stability of the three AA configurations does not change with coverage and their energies are ranked from -100 to $-40 \mathrm{~kJ}$. Interestingly, the $\mathrm{AA}_{(100)}^{2}$ configuration involving covalent bonding on LAS site is the most sensitive to coverage effect and is destabilized at high coverage with respect to $\mathrm{AA}_{(100)}^{1}$. This result may have implications for further experimental characterization (beyond the scope of the present work), since adsorption modes, and hence their spectroscopic features, could be thus influenced by surface coverages. 
(a)

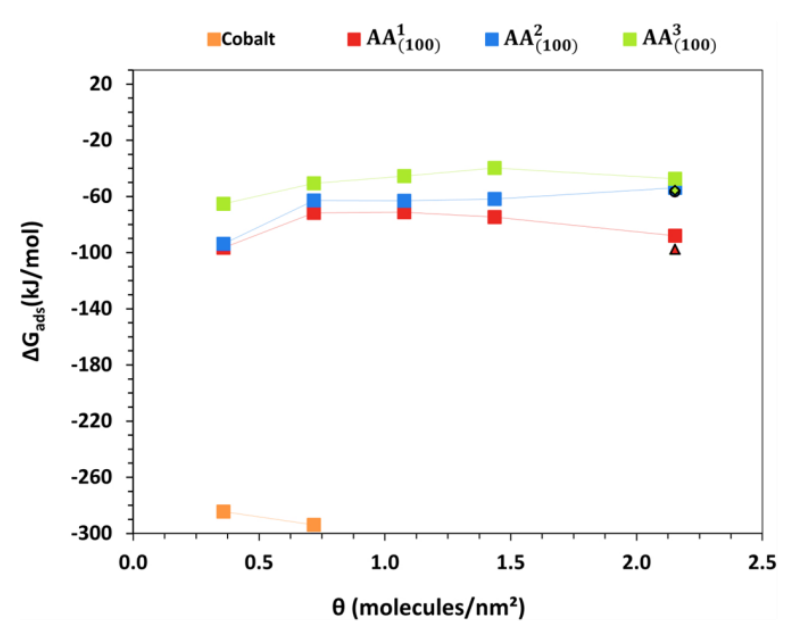

(c)

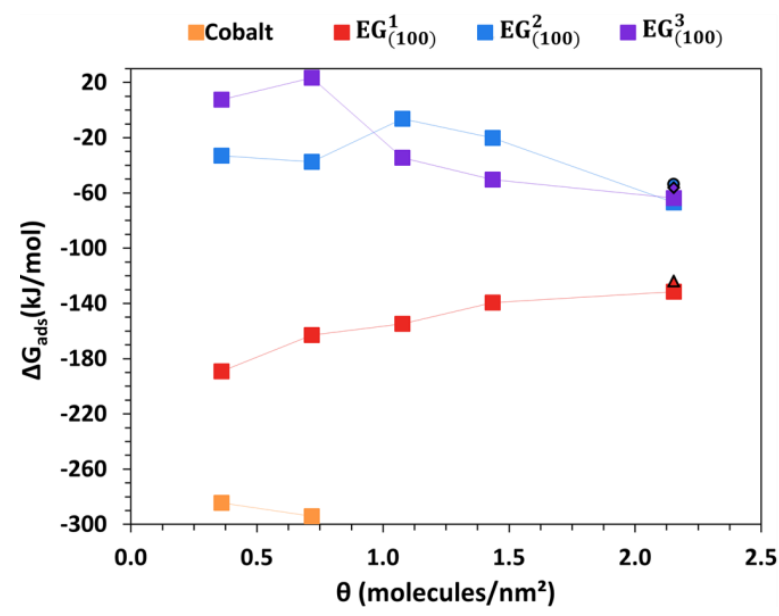

(b)

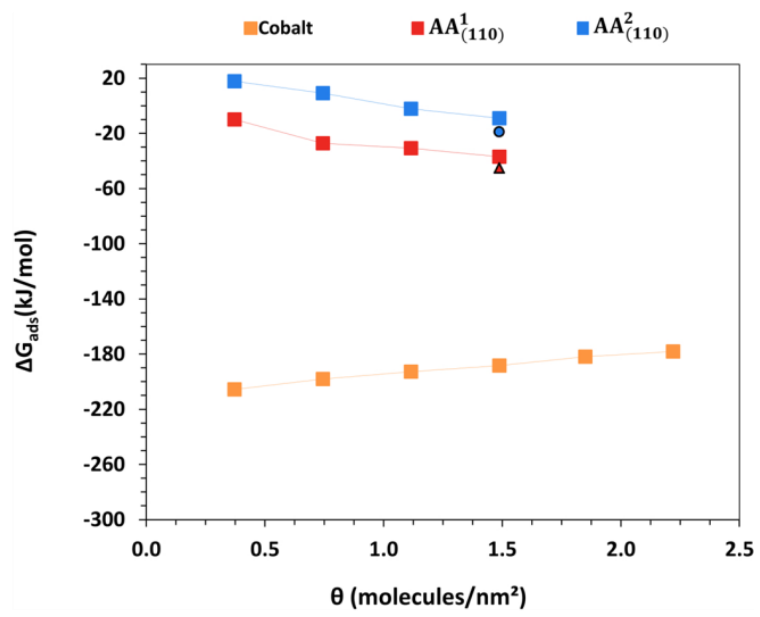

(d)

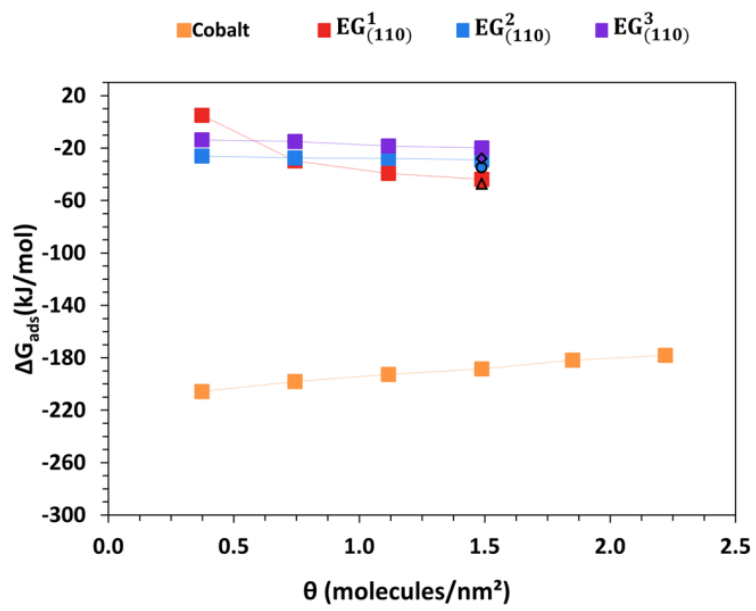

Figure 9. Adsorption free energy as a function of surface coverage on the (100) surface for AA (a) and for EG (c), and on the (110) surface for AA (b) and EG (d). In each case the cobalt adsorption free energy values were calculated in this work at the lowest coverage and the other values were exptrapolated based on the results of Ref. ${ }^{6}$. For each plot, the triangles, circles and diamonds are the respective free energy values of each configuration calculated in the small cells at $\theta_{(110)}=1.49$ molecules $/ \mathrm{nm}^{2}$ and $\theta_{(110)}=1.49$ molecules $/ \mathrm{nm}^{2}$.

The trends in surface coverage effects are the outcome of a trade-off between, on the one hand, surface-molecule and molecule-molecule interactions of adsorbates and, on the other hand, disrupted interactions between surface $\mathrm{OH}$ groups upon adsorption. The analysis of adsorption sites involved at $\theta_{(100)}=0.36 \mathrm{AA} / \mathrm{nm}^{2}$ (Figure S2.2b) and at $\theta_{(100)}=2.15 \mathrm{AA} / \mathrm{nm}^{2}$ 
(Figure 7b) shows that they are very similar in both cases, except for the $\mathrm{AA}_{(100)}^{2}$ configuration for which the molecule is in interaction through a hydrogen bond with an additional $\mu_{1}-\mathrm{OH}$ group at $\theta_{(100)}=0.36 \mathrm{AA} / \mathrm{nm}^{2}$. This $\mu_{1}-\mathrm{OH}$ (see the arrow on Figure $\mathrm{S} 2.2 \mathrm{a}$, and $\mathrm{S} 2.2 \mathrm{~b}$ ) is actually the one that is attached to the $\mathrm{Al}_{\mathrm{V}}$ sites, and which is desorbed (in the form of a $\mathrm{H}_{2} \mathrm{O}$ molecule after combining with the AA dissociated proton) prior to AA adsorption on that $\mathrm{Al}_{\mathrm{v}}$ site. Hence as $\theta$ decreases more of these $\mathrm{OH}$ groups become available to interact for a given AA molecule present on the surface. It is also clear from Figures $7 \mathrm{~b}$ and S2.1b that the hydrogen bonds and covalent bonds distances do not change dramatically for different $\theta$ values. It follows from these observations that the slight free energy fluctuations that occur upon changing the $\theta$ value, do not appear to be directly influenced by the local structural changes around the adsorbed molecules, but are rather due to lateral interactions: surface molecule-molecule interaction and hydrogen bond networks disruption. In particular, in the $\mathrm{AA}_{(100)}^{3}$ configuration, there are only 3 interaction sites attaching $\mathrm{AA}$ to the surface (Figures $7 \mathrm{~b}$ and $\mathrm{S} 2.1 \mathrm{~b}$ ). In this case the molecule-surface interactions created on the surface by the incoming molecule do not compensate the hydroxyl-hydroxyl interactions loss which bring a more important stabilizing contribution at $\theta_{(100)}=0.36 \mathrm{AA} / \mathrm{nm}^{2}$ than at $\theta_{(100)}=2.15$ $\mathrm{AA} / \mathrm{nm}^{2}$. By contrast, $\mathrm{AA}_{(100)}^{1}$ exhibits twice as many interacting sites (6) on the surface (Figures $7 \mathrm{~b}$ and S2.2b). This significantly increases the contribution from molecule-surface interactions at $\theta_{(100)}=2.15 \mathrm{AA} / \mathrm{nm}^{2}$ and reduces the energy difference with that at $\theta_{(100)}=$ $0.36 \mathrm{AA} / \mathrm{nm}^{2}$ (Figures $7 \mathrm{~b}$ and $\mathrm{S} 2.2 \mathrm{~b}$ ). For the $\mathrm{AA}_{(100)}^{2}$ configuration, there are also many interaction sites on the surface to enhance molecule-surface interactions contributions at $\theta_{(100)}$ $=2.15 \mathrm{AA} / \mathrm{nm}^{2}$. However, water molecules are desorbed from the surface during the adsorption process, and the energy cost associated with the multiple desorption reactions is higher than the stabilizing contribution arising from the numerous molecule-surface and molecule-molecule interactions at $\theta_{(100)}=2.15 \mathrm{AA} / \mathrm{nm}^{2}$. 


\section{Ethylene glycol}

The adsorption reaction of EG molecules on the (100) surface is exergonic at all $\theta$ values, except for the $\mathrm{EG}_{(100)}^{3}$ configuration at $\theta_{(100)}=0.72 \mathrm{EG} / \mathrm{nm}^{2}$, and for the $\mathrm{EG}_{(100)}^{2}$ configuration at $\theta_{(100)}=1.08 \mathrm{EG} / \mathrm{nm}^{2}$ (Figure 9c). Two different trends are observed for EG: when $\theta$ increases, the adsorption free energy decreases for the $\mathrm{EG}_{(100)}^{1}$ configuration (hydrogen bonded) whereas it fluctuates for the $\mathrm{EG}_{(100)}^{2}$, and $\mathrm{EG}_{(100)}^{3}$ configurations (covalently bonded)). This trend thus differs from the AA molecule. However, the $\mathrm{EG}_{(100)}^{1}$ configuration remains the most stable at all $\theta$ values studied in this work.

According to our structural analysis, unlike AA, the nature of surface interacting hydroxyls with EG are notably changed between the lowest and highest $\theta$ values, which explains also why the energy values depend more strongly on the coverage than for AA (fluctuations up to $70 \mathrm{~kJ} / \mathrm{mol}$ for EG vs $40 \mathrm{~kJ} / \mathrm{mol}$ for AA). As previously mentioned and as illustrated in Figure 7a and 7c, the C-C backbone of EG lies parallel to the surface whereas the one of AA is perpendicular or tilted. It appears from Figure 7c and S2.2c that for the $\mathrm{EG}_{(100)}^{1}$ configuration, the contribution coming from the growing number of molecule-surface interactions at $\theta_{(100)}=2.15 \mathrm{EG} / \mathrm{nm}^{2}$ is weaker than the contribution from surface-surface interactions disrupted from the surface coverage at $\theta_{(100)}=0.36 \mathrm{EG} / \mathrm{nm}^{2}$. Moreover, as we can see in Figure 6c, at $\theta_{(100)}=2.15 \mathrm{EG} / \mathrm{nm}^{2}$ the $\mathrm{EG}$ molecules are not in close contact with each other and this reduces the contribution from molecule-molecule interactions to the free energy. As a consequence, the $E G$ adsorption on the (100) surface in the $E G_{(100)}^{1}$ configuration is more favorable at low $\theta$ values. For the $\mathrm{EG}_{(100)}^{2}$, and $\mathrm{EG}_{(100)}^{3}$ configurations, we can see in Figure $7 \mathrm{c}$ that the orientation of the adsorbed EG molecules on the surface encourages them to interact with each other at $\theta_{(100)}=2.15 \mathrm{EG} / \mathrm{nm}^{2}$. As a result the combination of these molecule-molecule and molecule-surface interactions is so important 
that, it not only compensates for the energy cost of disrupting the multiple $\mathrm{H}_{2} \mathrm{O}$ desorption reactions at $\theta_{(100)}=2.15 \mathrm{EG} / \mathrm{nm}^{2}$, but also stabilizes the adsorbed configurations. In addition, for the $\mathrm{EG}_{(100)}^{3}$ configuration, there are hydrogens bonds between the EG molecules at $\theta_{(100)}=$ 2.15 EG/nm² (Figure 6c). This reinforces the stability of that configuration as the energy gain we observe between $\theta_{(100)}=0.36 \mathrm{EG} / \mathrm{nm}^{2}$ and $\theta_{(100)}=2.15 \mathrm{EG} / \mathrm{nm}^{2}$ is more important in comparison to that of the $\mathrm{EG}_{(100)}^{2}$ configuration (Figure $7 \mathrm{~d}$ and $\mathrm{S} 2.2 \mathrm{~d}$ ).

\subsection{2 (110) surface}

\section{Acetic acid}

Contrary to the (100) surface, the adsorption free energy of AA on the (110) surface becomes more exergonic with increasing surface coverage for both $\mathrm{AA}_{(110)}^{1}$, and $\mathrm{AA}_{(110)}^{2}$ configurations (Figure 9b). The $\mathrm{AA}_{(110)}^{1}$ configuration is always more stable than the $\mathrm{AA}_{(110)}^{2}$ configuration. However, the energies remain significantly lower than on the (100) in both cases. Moreover, the impact of the coverage is weak and it is coherent with the fact that no significant local structural changes occur around the AA molecule (Figures $8 \mathrm{~b}$ and S2.3b). As for the (100) surface, since the C-C backbone of the AA molecule is nearly perpendicular to surface, the lateral interactions are expected to be small as illustrated in Figure 8a. A weak molecule-molecule interaction may contribute to the stabilization of the system with increasing coverage.

\section{Ethylene glycol}

According to Figure 9d the adsorption free energy of EG on the (110) surface slightly increases with surface coverage for the three adsorption configurations. However, this fluctuation remains moderate which is compatible with the moderate structural change observed (Figure 7d and S2.3d). This free energy increase is more significant and more rapid 
for the $\mathrm{EG}_{(110)}^{1}$ than for the $\mathrm{EG}_{(110)}^{2}$, and $\mathrm{EG}_{(110)}^{3}$ configurations. Moreover, $\mathrm{EG}_{(110)}^{1}$ becomes the most stable configuration for $\theta_{(110)} \geq 0.74 \mathrm{EG} / \mathrm{nm}^{2}$ whereas it is the less stable configuration when $\theta_{(110)}=0.37 \mathrm{EG} / \mathrm{nm}^{2}$.

\subsection{Comparison between oxygenates and cobalt(II)}

\subsubsection{Energetic analysis}

Knowing the structural features and adsorption free energy values of the most favorable adsorption configurations of AA and EG on the (100) and (110) surfaces of $\gamma$ alumina, we now compare these data with those deduced from the adsorbed cobalt complex $\mathrm{Co}\left(\mathrm{H}_{2} \mathrm{O}\right)_{2}$ previously studied in reference ${ }^{6}$ to identify the possible competition between organic-surface interactions and metal-surface interactions.

First of all, we point out that the formation of $\mathrm{Co}\left(\mathrm{H}_{2} \mathrm{O}\right)_{2}$ complexes on the (100) surface is more favorable than on the (110) surface, whatever the coverages (Figure 9). This trend is thus similar as for the adsorption of AA and EG molecules. .

The analysis of the adsorption of the Cobalt species on both alumina surfaces (after drying) reported in Figure 9 indicates that the overall process (the sum of equations $a$ and $b$ in Figure 5) is an exergonic reaction, and the corresponding free energy values are always far more exergonic than those of AA and EG. On the (100) surface (Figures 9a and 9b) the adsorption of a $2^{\text {nd }}$ cobalt complex is slightly more favorable than that of the first $1^{\text {st }}$ one, unlike what we observe for almost all AA and EG configurations. Regarding the (110) surface, the $\mathrm{Co}\left(\mathrm{H}_{2} \mathrm{O}\right)_{2}$ adsorption free energy becomes slightly less exergonic with increasing $\theta$ value, whereas that of AA and EG increase. Nevertheless, at $\theta_{(110)}=1.49 \mathrm{Co}\left(\mathrm{H}_{2} \mathrm{O}\right)_{2} / \mathrm{nm}^{2}$ the adsorption free energy remains significantly more exergonic than that of AA or EG. 
We must point out here that the $\Delta \mathrm{G}$ values reported in Figure 9 corresponds to the impregnation of the metal salt followed by the thermal decomposition of the nitrate counterion into $\left(\mathrm{N}_{2}+5 / 2 \mathrm{O}_{2}\right)$ after drying. The reaction free energyof nitrate decomposition (equation b in Figure 5)is $-206 \mathrm{~kJ} / \mathrm{mol}$ at the considered drying conditions ( $\mathrm{T}=298 \mathrm{~K}$ ). As a consequence the free energy for the adsorption of $\mathrm{Co}\left(\mathrm{H}_{2} \mathrm{O}\right)_{2}$ complexes on the (100) and (110) surfaces are thus far less exergonic : -79 and $0 \mathrm{~kJ} / \mathrm{mol}$, respectively (equation a in Figure 5). The latter $\Delta \mathrm{G}$ values do not depend on the choice of the counter-ions, and stand for the intrinsic process of the formation of the dried surface $\mathrm{Co}\left(\mathrm{H}_{2} \mathrm{O}\right)_{2}$ complexes(without involving the counter-ions decomposition) leading to 4 water molecules released in gas phase and the two solvated protons. The corresponding internal energies of the adsorption of $\mathrm{Co}\left(\mathrm{H}_{2} \mathrm{O}\right)_{2}$ complexes (after drying) are $\Delta \mathrm{U}_{(100)}^{\text {Cobalt }}=+62$ and $\Delta \mathrm{U}_{(110)}^{\text {Cobalt }}=+141 \mathrm{~kJ} / \mathrm{mol}$, which highlights the entropic effect induced by the release of the $4 \mathrm{H}_{2} \mathrm{O}$ moleculesin gas phase (see also section $\mathrm{S} 3$ of supplementary materials) at $298 \mathrm{~K}$. This implies thus a much larger entropic contribution in favor of $\mathrm{Co}\left(\mathrm{H}_{2} \mathrm{O}\right)_{2}$ compared to AA and EG for which zero or one $\mathrm{H}_{2} \mathrm{O}$ molecule is released in the gas phase upon adsorption and after drying. This entropic effect is amplified by the simultaneous decomposition of the nitrate counter-ions. Hence, for the drying process explored so far, the free energy balance is clearly in favor of the cobalt precursor.

However, depending on the impregnation/drying conditions, the free energy balance for the organic molecules adsorbed at the surface may compete with the one of cobalt precursors. To reach such conditions, we may first suggest to consider either other Co(II) precursors or other counter-ions which would impact either the internal energy of the solvated Co(II) precursors or the entropic contributions induced by the release or decomposition of the counter-ions and ligands. For instance, if a stronger ligand substitute water in the internal sphere of the $\mathrm{Co}(\mathrm{II})$ precursors, the internal energy balance of equation $\mathrm{c}$ in Figure 5 will 
become less favorable to cobalt complexes formation. Lastly, if we qualitatively consider the conditions reached at the impregnation step of (before the drying step), all entropic effects due to the final state are significantly reduced. The $\Delta \mathrm{G}$ values of adsorbed $\mathrm{Co}\left(\mathrm{H}_{2} \mathrm{O}\right)_{2}$ complexes would become closer to the previous estimates $(-79 \mathrm{~kJ} / \mathrm{mol}$ and $0 \mathrm{~kJ} / \mathrm{mol})$ following equation (a) in Figure 15. These $\Delta \mathrm{G}$ values become less favorable with respect to those calculated for AA and EG molecules. Although this quantitative analysis requires dedicated calculations dealing with the solvated adsorbed species (beyond the scope of the present work), we suspect from this qualitative analysis that the organic molecule may compete more easily with $\mathrm{Co}\left(\mathrm{H}_{2} \mathrm{O}\right)_{2}$ complexes for the surface during impregnation steps (in the solvated state). If so, the displacement of the strongly interacting $\mathrm{Co}\left(\mathrm{H}_{2} \mathrm{O}\right)_{2}$ complexes by the molecules will be enhanced if kinetic limitations are involved during the drying process.

\subsubsection{Structural analysis of adsorption site competition}

Figures 10 and 11 summarize the locations of $\mathrm{Co}\left(\mathrm{H}_{2} \mathrm{O}\right)_{2}$, AA and EG according to their most favorable adsorption configurations at the lowest coverages studied here on the (100) and (110) surfaces, respectively. Regarding the cobalt species, in order to better depict the effect of surface coverage, we also represent schematically the various cobalt complexes in epitaxial interactions with both surfaces at high cobalt coverages according to the previous proposals ${ }^{6}$. On the (100) surface, the first adsorbed cobalt complex sits at the edge of a surface cavity (Figure 10), and the same applies for AA and EG, regardless of the adsorption configuration.Moreover, according to the previous work ${ }^{6}$, by increasing the coverages on the 
(100) surface, the $\mathrm{Co}\left(\mathrm{H}_{2} \mathrm{O}\right)_{2}$ complexes preferentially sit in an epitaxial configuration, and the subsequent $\mathrm{Co}\left(\mathrm{H}_{2} \mathrm{O}\right)_{2}$ complexes reside also at the edge of a (100) surface cavity. This leads to two possible epitaxial relationships either along the $\mathrm{x}$-direction or the $\mathrm{y}$-direction of the cell. Hence, we can suggest that if AA and EG molecules are pre-impregnated on the surface before cobalt adsorption, they might break the epitaxial relationship involving some $\mathrm{Co}\left(\mathrm{H}_{2} \mathrm{O}\right)_{2}$ complexes particularly those located along the x-direction (light blue square). However, the complete hindering of Cobalt complexes could be possible only if the surface coverages of EG and AA must reach 2.15 molecule per $\mathrm{nm}^{2}$ at least so that all cavities are occupied and cannot interact anymore with $\mathrm{Co}\left(\mathrm{H}_{2} \mathrm{O}\right)_{2}$ complexes. . Moreover, considering their main adsorption sites, the AA and EG molecules do not seem to be able to prevent the epitaxial growth of cobalt complexes along the y-direction. Only in the case of $\mathrm{EG}_{(100)}^{2}$, there is a competition for the same adsorption site, these two molecules should not play an important role in inhibiting the strong interaction of cobalt complexes with the (100) surface after drying. Regarding the AA molecule, this result is consistent with in situ infra-red spectroscopy experiments showing that AA does not impact the sorption of cobalt on $\gamma$ alumina support and that the precipitation of cobalt hydroxide or cobalt-aluminum hydrotalcite occurs 56 . 


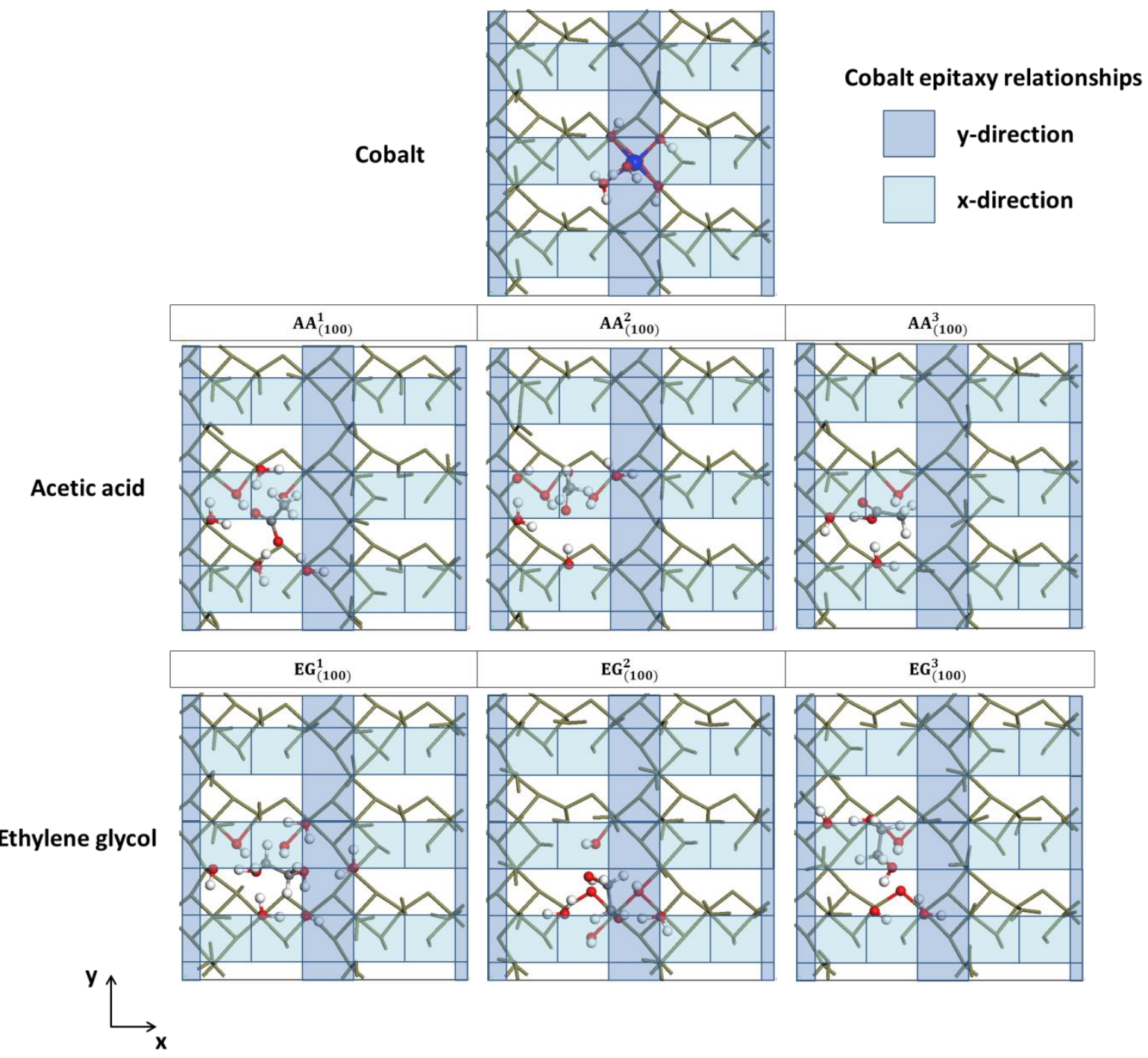

Figure 10. Top views of the (100) surface showing the location of the adsorbed species: Cobalt, acetic acid, and ethylene glycol at the lowest surface coverage $\left(0.36\right.$ species per $\left.\mathrm{nm}^{2}\right)$ The blue squares represent schematically the two directions for the epitaxial relationships of the Co complexes at higher coverages (light blue: 6.70 Co atoms per $\mathrm{nm}^{2}$, dark blue: $4.47 \mathrm{Co}$ atoms per $\mathrm{nm}^{2}$ ) according to the schemes proposed in Ref. ${ }^{6}$. The adsorbed species and interacting $\mathrm{OH}$ groups are colored as follows: grey (carbon), red (oxygen), white (hydrogen), and blue (cobalt). The dark green color is used for all other surface atoms.

On the (110) surface, Figure 11 illustrates that the $\mathrm{AA}_{(110)}^{1}$ configuration of AA may compete for the same surface site as the cobalt complex. This is not the case for $\mathrm{AA}_{(110)}^{2}$. Regarding the $\mathrm{EG}$ molecule, by contrast, $\mathrm{EG}_{(110)}^{1}$ and $\mathrm{EG}_{(110)}^{3}$ configurations do not sit neither at the same site as the cobalt complex nor on the same row of the epitaxy relationship ${ }^{6}$. 
Figure 11 reports the scheme proposed by these authors who found an epitaxial relationship along the y-direction. According to this representation, $\mathrm{EG}_{(110)}^{2}$ is a configuration prone to hinder the epitaxy because it is located on the same row where the cobalt chains may grow. So from a structural point of view, the molecules are able to compete with cobalt for the anchoring sites and we cannot exclude that the EG and AA may impact the interaction of cobalt species with this alumina (110) surface particularly in the $\mathrm{AA}_{(110)}^{1}$ and $\mathrm{EG}_{(110)}^{2}$ configurations.

As previously discussed, from the energetic point of view, the competition is thermodynamically strongly in favor of cobalt-surface interaction after drying at RT. So, one should attempt to compensate it by using a sufficient concentration of organic compounds during a pre-impregnation step of the surface to pre-cover the surface the anchoring sites of cobalt. As for the (100) surface, one may assume that the epitaxial growth can only be prevented by AA and EG molecules at the early stage of the cobalt impregnation step once the alumina surface has been impregnated by the organic molecules and when entropic effects are minimized by the solvent. After drying, cobalt should displace both EG/AA molecules according to the thermodynamic driving forces. If one assume that kinetic limitations will prevent the displacement of the organic molecules by cobalt complexes during drying, the effect of EG/AA can be also effective after drying. This aspect remains to be investigated by further theoretical calculations. 


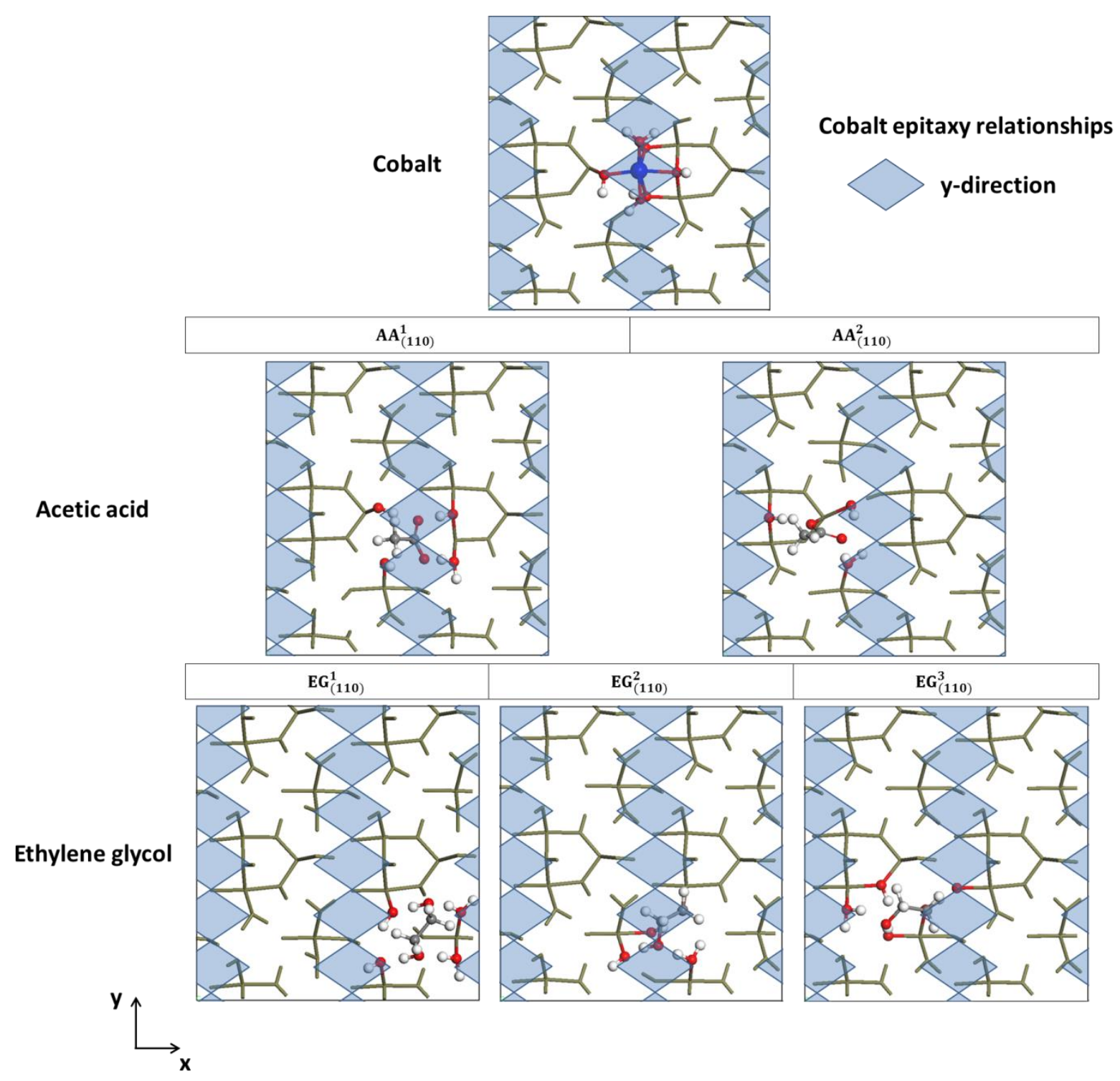

Figure 11. Top views of the (110) surface showing the location of the adsorbed species (Cobalt, acetic acid, and ethylene glycol) at the lowest surface coverage ( 0.37 species per $\mathrm{nm}^{2}$ ) The blue losanges represent schematically the epitaxial interaction of the Co complexes at higher coverages ( 4.44 Co atoms $/ \AA^{2}$ ), according to the schemes proposed in Ref. ${ }^{6}$. The interacting surface sites and the species are highlighted with the following colors: grey (carbon), red (oxygen), white (hydrogen), and blue (cobalt). The dark green coloris used for all other surface atoms. 


\section{Conclusions}

Using periodic DFT calculations, the potential energy surface of two oxygenated organic additives, namely acetic acid (AA) and ethylene glycol (EG) adsorbed on the (100) and (110) surfaces of $\gamma$-alumina, have been explored. These molecules are potential candidates for tuning cobalt-surface interactions during catalysts preparation. The interactions of these molecules with the above mentioned surfaces were studied in order to find their preferred adsorption modes and adsorption sites, as well as their adsorption free energies. Several adsorption modes were then identified for both molecules on the two surfaces and, for both AA and EG, the most favorable configurations on a given surface are Brønsted adsorption modes involving only hydrogen bonds connections between the molecule and the surface. In particular, a strong interaction of EG with the hydroxyls nests (cavities) of the (100) surface has been found. The molecules can also bind to the surfaces through a covalent bond in a Lewis adsorption mode, but the obtained structures are less energetically favorable than the previous ones. In fact for a given molecule, the comparison of the adsorption free energies of its most probable adsorption configurations indicate that AA is likely to form a covalent bond with the two $\gamma$-alumina surfaces, whereas EG would most probably do so only on the (110) surface. In general both molecules have a much higher affinity for the (100) surface than to the (110) surface, and both surfaces have a higher affinity for EG than for AA.

Since the surface coverage $(\theta)$ is also an important parameter in catalysts preparation, for the most probable configurations found for each molecule, we varied the number of adsorbed species and monitor the changes in the structure and adsorption free energies. For a given molecule (AA/EG) the free energy changes as a function of $\theta$ varies with the type of 
surface and with the nature of the adsorption configuration. On the (100) surface, the adsorption free energies of the three AA configurations decrease with increasing $\theta$ value, while on the (110) surface the adsorption free energies increase as surface coverage increases. For EG on the (100) surface, if covalent bonds are involved in EG-surface interactions (LAS), high $\theta$ values are more favorable. However if only hydrogen bonds link the molecule to the surface (BAS), low $\theta$ values are then preferred. On the (110) surface, the adsorption free energies of the EG configurations with a covalent bond are almost invariant, while the free energy of structures with only hydrogen bonds with the surface lowers with decreasing $\theta$ value. In all cases our data show that the structures of adsorption configurations are hardly affected by the changes in surface coverages, so that the observed energy changes are only related to, on the one hand, the number and the type of surface-molecule and moleculemolecule interactions and, on the other hand, the extent to which surface $\mathrm{OH}$ groups are disrupted by the incoming molecule.

A comparison with the adsorption of the $\mathrm{Co}\left(\mathrm{H}_{2} \mathrm{O}\right)_{2}$ complex has been undertaken to explore if the surface-molecule interactions can help us to predict the influence of these molecules on surface- $\mathrm{Co}\left(\mathrm{H}_{2} \mathrm{O}\right)_{2}$ interactions. As for AA and EG, the $\mathrm{Co}\left(\mathrm{H}_{2} \mathrm{O}\right)_{2}$ complex have a higher affinity for the (100) surface relatively to the (110) surface. However, after drying, both surfaces showed a significantly higher affinity for the $\mathrm{Co}\left(\mathrm{H}_{2} \mathrm{O}\right)_{2}$ complex than for any of the two molecules and for both surfaces the affinity order is: $\mathrm{Co}\left(\mathrm{H}_{2} \mathrm{O}\right)_{2} \gg \mathrm{EG}>$ AA. From the analyses of the surface locations of the organic species, and by comparing them with cobalt epitaxial structures proposed in a previous work ${ }^{6}$, we have identified some relevant configurations where two molecules may compete for the same adsorption sites as the ones involved in $\mathrm{Co}\left(\mathrm{H}_{2} \mathrm{O}\right)_{2}$ adsorption. However, since the thermodynamic analysis (after drying) revealed that the cobalt species have significantly stronger adsorption free energies than the two molecules, the impact of EG and AA may be predominant at an early stage of 
impregnation step when the entropic contribution of the gas phase products formed upon drying is minimized. More particularly, these molecules can eventually be efficient if two consecutive impregnation steps of alumina are used: the first one involving the organic molecules only and the second one the cobalt precursors assuming that kinetic limitations may also take place during drying. In order to validate this concept we may propose as a challenging perspective of the present work to investigate the kinetic aspects of the adsorption and desorption processes in presence of an implicit representation of the aqueous solvent. Hopefully, the present study may already offer relevant insights for a more rational understanding of the preparation steps of alumina supported catalysts and may open the route for further investigations on different organic molecules and metallic precursors.

\section{ASSOCIATED CONTENT}

Supporting Information.

S1. Details of our simulated systems

S2. Snapshots of acetic acid and ethylene glycol configurations at the lowest surface coverage

S3. Calculation of the adsorption free energies

S4: Extrapolation of adsorption data from Larmier et al. ${ }^{6}$

This material is available free of charge via the Internet at http://pubs.acs.org.

\section{AUTHOR INFORMATION}

Corresponding Authors 
Manuel Corral Valero, manuel.corral-valero@ifpen.fr

Author Contributions

The manuscript was written through contributions of all authors. All authors have given approval to the final version of the manuscript.

Acknowledgements

This work was supported by the French National Research Agency within the framework of the ANR-14-CE08-0019 SLIMCAT project. This work was performed using HPC resources from GENCI-CINES (Grant A0020807386 ).

\section{References}

(1) Euzen, P.; Raybaud, P.; Krokidis, X.; Toulhoat, H.; Le Loarer, J. L.; Jolivet, J. P.; Froidefond, C. Alumina. Handbook of Porous Solids; Wiley-VCH Verlag GmbH, 2008; pp 1591-1677.

(2) Mitchell, S.; Michels, N. L.; Pérez-Ramirez, J. From powder to technical body: the undervalued science of catalyst scale up. Chem. Soc. Rev. 2013, 42, 6094-6112.

(3) Munnik, P.; de Jongh, Petra E; de Jong, Krijn P. Recent Developments in the Synthesis of Supported Catalysts. Chem. Rev. 2015, 115, 6687-6718.

(4) Che, M. Interfacial Coordination Chemistry - Concepts and Relevance to Catalysis Phenomena. Stud. Surf. Sci. Catal. 1993, 75, 31-68.

(5) Bourikas, K.; Kordulis, C.; Lycourghiotis, A. The Role of the Liquid-Solid Interface in the Preparation of Supported Catalysts. Catal. Rev. 2006, 48, 363-444.

(6) Larmier, K.; Chizallet, C.; Raybaud, P. Tuning the Metal-Support Interaction by Structural Recognition of Cobalt-Based Catalyst Precursors. Angew. Chem. Int. Ed. 2015, 54, 68246827.

(7) Digne, M.; Raybaud, P.; Sautet, P.; Guillaume, D.; Toulhoat, H. Quantum chemical and vibrational investigation of sodium exchanged [gamma]-alumina surfaces. Phys. Chem.

Chem. Phys. 2007, 9, 2577-2582. 
(8) Louwerse, M. J.; Rothenberg, G. Modeling Catalyst Preparation: The Structure of Impregnated-Dried Copper Chloride on Y-Alumina at Low Loadings. ACS Catal 2013, 3, 15451554.

(9) Zhang, J.; Chen, J.; Ren, J.; Sun, Y. Chemical Treatment of $\mathrm{Y}$-Al2O3 and its Influence on the Properties of Co-based Catalysts for Fischer-Tropsch Synthesis. Appl. Catal. A Gen. 2003, $243,121-133$.

(10) Abi Aad, J.; Courty, P.; Decottignies, D.; Michau, M.; Diehl, F.; Carrier, X.; Marceau, E. Inhibition by Inorganic Dopants of $y$-Alumina Chemical Weathering under Hydrothermal Conditions: Identification of Reactive Sites and their Influence in Fischer-Tropsch Synthesis. ChemCatChem 2017, 9, 2106-2117.

(11) Catalysis by Transition Metal Sulphides. From Molecular Theory to Industrial Application; Toulhoat, H.; Raybaud, P., Eds.; Editions Technip: Paris, 2013.

(12) Sarrazin, P.; Kasztelan, S.; Payen, E.; Bonnelle, J. P.; Grimblot, J. Interaction of Oxomolybdenum Species with $\gamma$-alumina and $\gamma$-alumina Modified by Silicon. 2 . The molybdena/ $\gamma$-alumina and molybdena/silica/ $\gamma$-alumina Systems. The Journal of Physical Chemistry 1993, 97, 5954-5961.

(13) Tougerti, A.; Llorens, I.; D'Acapito, F.; Fonda, E.; Hazemann, J. L.; Joly, Y.; Thiaudière, D.; Che, M.; Carrier, X. Surface Science Approach to the Solid-Liquid Interface: SurfaceDependent Precipitation of $\mathrm{Ni}(\mathrm{OH}) 2$ on $\alpha$-Al2O3 Surfaces. Angew. Chem. Int. Ed. 2012, 51, 7697-7701.

(14) Tougerti, A.; Methivier, C.; Cristol, S.; Tielens, F.; Che, M.; Carrier, X. Structure of Clean and Hydrated $\alpha$-Al2O3 (1-102) Surfaces: Implication on Surface Charge. Phys. Chem. Chem. Phys. 2011, 13, 6531-6543.

(15) Naoto Koizumi; Takehisa Mochizuki; Muneyoshi Yamada. Preparation of Highly Active Catalysts for Ultra-Clean Fuels. Catal. Today 2009, 141, 34-42.

(16) Costa, V.; Guichard, B.; Digne, M.; Legens, C.; Lecour, P.; Marchand, K.; Raybaud, P.; Krebs, E.; Geantet, C. A rational interpretation of improved catalytic performances of additive-impregnated dried CoMo hydrotreating catalysts: a combined theoretical and experimental study. Catal. Sci. Technol. 2013, 3, 140-151.

(17) Nicosia D.; Prins, R. The effect of glycol on phosphate-doped CoMo/AlO hydrotreating catalysts. J. Catal. 2005, 229, 424-438. 
(18) Jean-Marie, A.; Griboval-Constant, A.; Khodakov, A. Y.; Diehl, F. Influence of SubStoichiometric Sorbitol Addition Modes on the Structure and Catalytic Performance of Alumina-supported Cobalt Fischer-Tropsch Catalysts. Catal. Today 2011, 171, 180-185. (19) Borg, Ø.; Dietzel, Pascal D. C.; Spjelkavik, A. I.; Tveten, E. Z.; Walmsley, J. C.; Diplas, S.; Eri, S.; Holmen, A.; Rytter, E. Fischer-Tropsch Synthesis: Cobalt Particle Size and Support Effects on Intrinsic Activity and Product Distribution. J. Catal. 2008, 259, 161-164. (20) Bonduelle-Skrzypcak, A.; Guichard, B. Where Coordination Chemistry Meets HDT Catalyst Synthesis Organic Additives. In Catalysis by Transition Metal Sulphides. From Molecular Theory to Industrial Application; Toulhoat, H., Raybaud, P., Eds.; Editions Technip: Paris, 2013; pp 181-208.

(21) Dumond F.; Marceau, E.; Che, M. A Study of Cobalt Speciation in Co/Al2O3 Catalysts Prepared from Solutions of Cobalt-Ethylenediamine Complexes. J. Phys. Chem. C 2007, 111, 4780-4789.

(22) Jiao, W. Q.; Wang, Y. M.; He, M.-Y. Morphology-controlled Synthesis of Y-Al2O3 with Large Mesopores Through Combustion of Aluminum Carboxylate Salts. Microporous Mesoporous Mater. 2013, 181, 123-131.

(23) Stanislaus, A.; Al-Dolama, K.; Absi-Halabi, M. Preparation of a Large Pore Alumina-based HDM Catalyst by Hydrothermal Treatment and Studies on Pore Enlargement Mechanism. Fifteenth Indian National Symposium on Catalysis and Second Conference of the Indo-Pacific Catalysis Association 2002, 181, 33-39.

(24) Absi-Halabi, M.; Stanislaus, A.; Al-Zaid, H. Effect of Acidic and Basic Vapors on Pore Size Distribution of Alumina Under Hydrothermal Conditions. Appl. Catal. A Gen. 1993, 101, 117128.

(25) ZHANG Jun-Ling, CHEN Jian-Gang, DONG Qing-Nian, REN Jie, SUN Yu-Han. Adsorption and Reaction Behavior of FT Co Catalysts Supported by Chemically-modified Alumina. Chem. J. CHINESE U. 2003, 24, 301-304.

(26) Ravenelle, R. M.; Copeland, J. R.; Kim, W.-G.; Crittenden, J. C.; Sievers, C. Structural Changes of Y-Al2O3-Supported Catalysts in Hot Liquid Water. ACS Catal 2011, 1, 552-561. (27) Koichumanova, K.; Sai Sankar Gupta, K. B.; Lefferts, L.; Mojet, B. L.; Seshan, K. An in situ ATR-IR Spectroscopy Study of Aluminas Under Aqueous Phase Reforming Conditions. Phys. Chem. Chem. Phys. 2015, 17, 23795-23804. 
(28) Copeland, J. R.; Shi, X. R.; Sholl, D. S.; Sievers, C. Surface Interactions of C2 and C3 Polyols with $\gamma$-Al2O3 and the Role of Coadsorbed Water. Langmuir 2013, 29, 581-593. (29) Abi Aad, J.; Casale, S.; Michau, M.; Courty, P.; Diehl, F.; Marceau, E.; Carrier, X. Chemical Weathering of Alumina in Aqueous Suspension at Ambient Pressure: A Mechanistic Study. ChemCatChem 2017, 9, 2186-2194.

(30) Copeland, J. R.; Santillan, I. A.; Schimming, S. M.; Ewbank, J. L.; Sievers, C. Surface Interactions of Glycerol with Acidic and Basic Metal Oxides. J. Phys. Chem. C 2013, 117, $21413-21425$.

(31) Jongerius, A. L.; Copeland, J. R.; Foo, G. S.; Hofmann, J. P.; Bruijnincx, P. C. A.; Sievers, C.; Weckhuysen, B. M. Stability of Pt/Y-Al2O3 Catalysts in Lignin and Lignin Model Compound Solutions under Liquid Phase Reforming Reaction Conditions. ACS Catalysis 2013, 3, 464473.

(32) Digne, M.; Sautet, P.; Raybaud, P.; Euzen, P.; Toulhoat, H. Hydroxyl Groups on gammaAlumina Surfaces: A DFT study. J. Catal. 2002, 211, 1-5.

(33) Digne, M.; Sautet, P.; Raybaud, P.; Euzen, P.; Toulhoat, H. Use of DFT to Achieve a Rational Understanding of Acid-Basic Properties of gamma-Alumina Surfaces. J. Catal. 2004, $226,54-68$.

(34) Costa, D.; Arrouvel, C.; Breysse, M.; Toulhoat, H.; Raybaud, P. Edge Wetting Effects of gamma-Al2O3 and Anatase-TiO2 Supports by MoS2 and CoMoS Active Phases, a DFT Study. J. Catal. 2007, 246, 325-343.

(35) Valero, M. C.; Raybaud, P.; Sautet, P. Influence of the Hydroxylation of gamma-Al2O3 Surfaces on the Stability and Diffusion of Single Pd Atoms, a DFT Study. J. Phy. Chem. B 2006, 110, 1759-1767.

(36) Valero, M. C.; Raybaud, P.; Sautet, P. Interplay between Molecular Adsorption and Metal-Support Interaction for Small Supported Metal Clusters: $\mathrm{CO}$ and $\mathrm{C} 2 \mathrm{H} 4$ adsorption on Pd-4/gamma-Al2O3. J. Catal. 2007, 247, 339-355.

(37) Valero, M. C.; Raybaud, P.; Sautet, P. Nucleation of Pd-n ( $n=1-5)$ Clusters and Wetting of Pd particles on gamma-Al2O3 Surfaces. A Density Functional Theory Study. Phys. Rev. B 2007, 75.

(38) Hu, C. H.; Chizallet, C.; Mager-Maury, C.; Corral-Valero, M.; Sautet, P.; Toulhoat, H.; Raybaud, P. Modulation of Catalyst Particle Structure upon Support Hydroxylation. Ab initio insights into Pd13 and Pt13/Y-Al2O3. J. Catal. 2010, 274, 99-110. 
(39) Mager-Maury, C.; Bonnard, G.; Chizallet, C.; Sautet, P.; Raybaud, P. H2-Induced Reconstruction of Supported Pt Clusters: Metal-Support Interaction versus Surface Hydride. ChemCatChem 2011, 3, 200-207.

(40) Ngouana-Wakou, B. F.; Cornette, P.; Corral Valero, M.; Costa, D.; Raybaud, P. An Atomistic Description of the $y$-Alumina/Water Interface Revealed by Ab Initio Molecular Dynamics. J. Phys. Chem. C 2017, 121, 10351-10363.

(41) Trueba, M.; Trasatti, S. P. Y-Alumina as a Support for Catalysts: A Review of Fundamental Aspects. ChemInform 2005, 36, 3393.

(42) Kresse, G.; Furthmüller, J. Efficiency of Ab-Initio Total Energy Calculations for Metals and Semiconductors Using a Plane-Wave Basis Set. Comput. Mater. Sci. 1996, 6, 15.

(43) Kresse, G.; Furthmüller, J. Efficient Iterative Schemes for Ab Initio Total Energy Calculations Using a Plane-Wave Basis Set. Phys. Rev. B 1996, 54, 11169.

(44) Kresse; Hafner. Ab Initio Molecular Dynamics Simulation of the Liquid-MetalAmorphous-Semiconductor Transition in Germanium. Phys. Rev. B 1994, 49, 14251-14269. (45) Kresse; Hafner. Ab Initio Molecular Dynamics for Liquid Metals. Phys. Rev. B 1993, 47, 558-561.

(46) Perdew, J. P.; Burke, K.; Ernzerhof, M. Generalized Gradient Approximation Made Simple. Physical Review Letters 1996, 77, 3865-3868.

(47) Perdew, J. P.; Burke, K.; Ernzerhof, M. Generalized Gradient Approximation Made Simple [Phys. Rev. Lett. 77, 3865 (1996)]. Phys. Rev. Lett. 1997, 78, 1396.

(48) Blöchl. Projector Augmented-Wave Method. Phys. Rev. B 1994, 50, 17953-17979.

(49) Kresse, G.; Joubert, J. From Ultrasoft Pseudopotentials to the Projector AugmentedWave Method. Phys. Rev. B 1999, 59.

(50) Mathew, K.; Sundararaman, R.; Letchworth-Weaver, K.; Arias, T. A.; Hennig, R. G. Implicit Solvation Model for Density-Functional Study of Nanocrystal Surfaces and Reaction Pathways. J. Chem. Phys. 2014, 140, 84106.

(51) Grimme, S. Semiempirical GGA-type Density Functional Constructed with a Long-Range Dispersion Correction. J. Comp. Chem. 2006, 27, 1787.

(52) Monkhorst, H. J.; Pack, J. D. Special Points for Brillouin-Zone Integrations. Phys. Rev. B 1976, 13, 5188-5192. 
(53) Liu, D.; Ma, G.; Xu, M.; Allen, H. C. Adsorption of Ethylene Glycol Vapor on $\alpha-A \mid 2 O 3$ (0001) and Amorphous SiO2 Surfaces: Observation of Molecular Orientation and Surface Hydroxyl Groups as Sorption Sites. Environ. Sci. Technol. 2005, 39, 206-212.

(54) Arunan, E.; Desiraju, G. R.; Klein, R. A.; Sadlej, J.; Scheiner, S.; Alkorta, I.; Clary, D. C.; Crabtree, R. H.; Dannenberg, J. J.; Hobza, P. et al. Definition of the Hydrogen Bond (IUPAC Recommendations 2011). Pure Appl. Chem., PAC 2011, 83, 1637-1641.

(55) Chiche, D.; Chizallet, C.; Durupthy, O.; Chaneac, C.; Revel, R.; Raybaud, P.; Jolivet, J. Growth of Boehmite Particles in the Presence of Xylitol Morphology Oriented by the Nest Effect of Hydrogen Bonding. Phys. Chem. Chem. Phys. 2009, 11, 11310-11323.

(56) Davantès, A.; Schlaup, C.; Carrier, X.; Rivallan, M.; Lefèvre, G. In Situ Cobalt Speciation on $\mathrm{Y}$-Al2O3 in the Presence of Carboxylate Ligands in Supported Catalyst Preparation. J. Phys. Chem. C 2017, 121, 21461-21471.

\section{GRAPHICAL ABSTRACT}

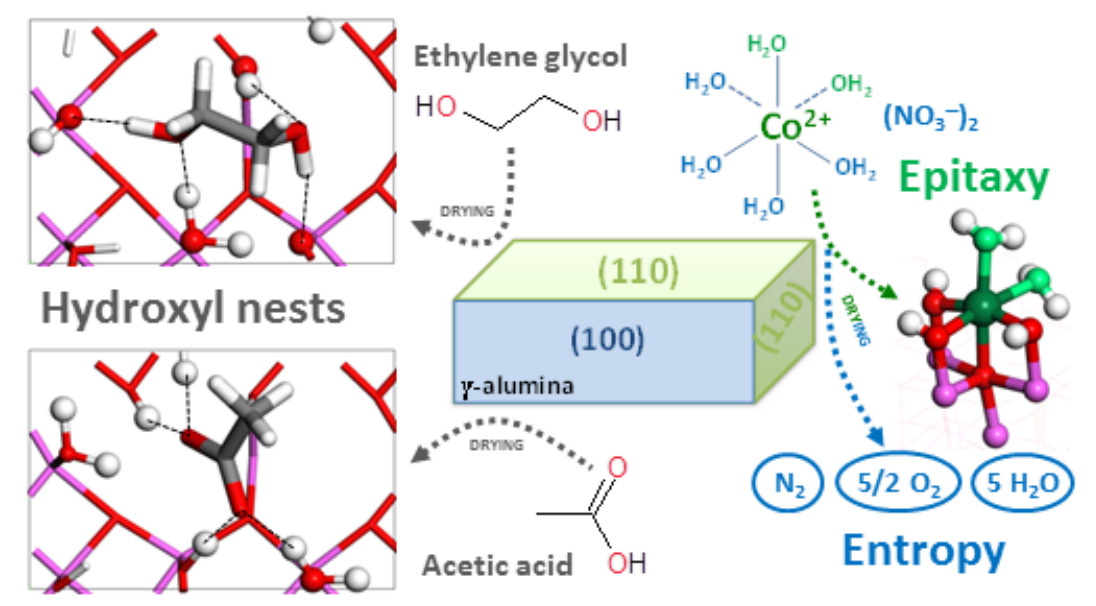

